This is a peer-reviewed, accepted author manuscript of the following article: Vassalos, D. (2020). The role of damaged ship dynamics in addressing the risk of flooding. Ships and Offshore Structures .

https://doi.org/10.1080/17445302.2020.1827639

\title{
The Role of Damaged Ship Dynamics in addressing the Risk of Flooding
}

\section{Dracos Vassalos ${ }^{1}$}

${ }^{1}$ Maritime Safety Research Centre, Department of Naval Architecture, Ocean and Marine Engineering, University of Strathclyde, Glasgow, Scotland, UK; d.vassalos@strath.ac.uk

\begin{abstract}
Ship dynamics, in the form of ship hydrodynamics with application to seakeeping, manoeuvring, resistance and propulsion, is now almost a century old. Most of these subjects with the emergence and rapid development of Computational Fluid Dynamics are now relying almost in full on numerical tools. Intact stability and capsizing in waves have also been introduced some 60 years ago. However, the dynamics of damaged ships in waves has persistently repelled close attention until the early 1980s when researchers at Strathclyde University tried to wake up this hibernating subject, following ground shaking accidents (Herald of Free Enterprise, 1987 and Estonia, 1994), the latter being the largest modern disaster in the western world with 852 people lost. Of course, in third world countries, disasters with 4,400 people perishing goes almost unnoticed (Dona Paz, the same year as the Herald of Free Enterprise). Research at Strathclyde in this particular area continues four decades later unabated, in the knowledge that damage stability problems in ships continue to be responsible for $90 \%$ of deaths in the maritime industry. For many years, I struggled to understand the reason for this but with age comes wisdom and cynicism: safety, even in the most advanced maritime nations of modern society, and the most progressive ship owners (with the exception of a pitifully small number) is still being perceived as unnecessary burden, limitation and cost and, as such, it receives attention only as damage reducing exercise. However, this could not be further from the truth. As a system, ship resilience is defined by her residual functionality post accidents and profitability by her safety margins, inbuilt and in operation. Design for safety and risk-based design, an ongoing effort for over three decades (also being brewed at Strathclyde), has made tremendous inroads in delivering the message that due attention to safety over the life-cycle of the vessel provides the right platform for a cost-effective economic activity whilst serving the higher societal goals. This paper targets to reinforce this belief by providing a methodological treatment of damage ship dynamics from the beginning of such developments to date whilst addressing the ensuing risk of flooding and offering solutions that have found their way in the maritime industry. For more details on developments on the subject prior to 2009, the reader should refer to [Vassalos, D. (2014)].
\end{abstract}

Keywords: damage stability; survivability, damaged ship dynamics; flooding risk management;

\section{Introduction}

The first risk control option, addressing flooding risk mitigation in the form of damage stability regulations, was introduced through the first Merchant Shipping Act in 1854 by way of subdivision and leading eventually and after heavy loss of life to the adoption of the first internationally agreed system of subdivision in SOLAS 1929. Similarly, the first specific criterion on residual static stability standards appeared at the 1960 SOLAS Convention, relating to the metacentric height being positive. Incremental changes in damage stability legislation followed, all in the aftermath of serious accidents, with important changes post-Herald of Free Enterprise and Estonia, the latter heralding break changes towards performance-based standards that led eventually to probabilistic damage stability rules that accelerated the change of development in an unprecedented way, transforming completely the legislative agenda. The sad story of accident-driven legislation and a record of disasters caused principally by flooding and addressing, in the main, western world casualties is portrayed in Table 1:

\begin{tabular}{|l|l|}
\hline Date & Disaster \\
\hline 1854 & $\begin{array}{l}\text { The first Merchant Shipping Act of } 1854 \text { is the first known legal requirement addressing safety at sea } \\
\text { and concerning watertight bulkheads. It was enacted as a direct result of the rapid foundering of the } \\
\text { Birkenhead in } 1852 \text { after striking a rock off South Africa drowning some } 500 \text { women and children. } \\
\text { The loss was rapid because the cavalry officers on board had holes cut in the transverse bulkheads in } \\
\text { order to exercise their horses. }\end{array}$ \\
\hline 1862 & $\begin{array}{l}\text { Pressure in Parliament by the ship owners succeeded in repelling the Act because it was simply based } \\
\text { on "mischievous" behaviour. Within three years the London and the Amelia both sank in the same } \\
\text { storm because of inadequate subdivision with } 233 \text { people drowning in the London alone. It is }\end{array}$ \\
\hline
\end{tabular}




\begin{tabular}{|c|c|}
\hline & $\begin{array}{l}\text { frightening that from } 1876-1892,10,381 \text { vessels belonging to the UK were totally lost with } 27,010 \\
\text { seamen and 3,543 passengers drowning, with losses attributed to "Acts of God". It is also worth noting } \\
\text { that in } 1878 \text { HMS "Eurydice" was lost with nearly } 400 \text { lives lost as the ship was caught by a strong } \\
\text { squall unprepared with some of her upper half-ports on the main deck open for ventilation and as she } \\
\text { heeled under the force of the wind, water entered the open ports causing a sudden and complete loss } \\
\text { of the ship. }\end{array}$ \\
\hline 1883 & $\begin{array}{l}\text { The Daphne capsized with the loss of } 124 \text { lives immediately after being launched in the Clyde. Sir } \\
\text { Edward Reed, the Commissioner of inquiry into the accident recommended that consideration should } \\
\text { be given of the extent to which stability entered into design, construction, stowage, load line and } \\
\text { freeboard of ships. }\end{array}$ \\
\hline 1891 & $\begin{array}{l}\text { The Bulkhead Committee of the British Board of Trade recommended a 2-compartment standard for } \\
\text { passenger ships but the recommendations were not adopted. Unbelievably, in many parts of the world, } \\
\text { one-compartment ships still exist, in spite of clear understanding today that the risk is completely "off } \\
\text { the scale". }\end{array}$ \\
\hline 1895 & $\begin{array}{l}\text { Germany introduced a 2-compartment standard, following the rapid loss of the Elbe with the death of } \\
340 \text { people. }\end{array}$ \\
\hline 1913 & $\begin{array}{l}\text { Following the Titanic catastrophe in April } 1912 \text { with a loss of 1,430 lives, the first International } \\
\text { Conference on the Safety of Life at Sea (SOLAS) takes place in London to consider proposals by UK, } \\
\text { Germany and France. The regulations formulated did not come into effect due to World War I. }\end{array}$ \\
\hline 1814 & $\begin{array}{l}\text { The Empress of Ireland capsised in the Gulf of St. Lawrence with } 1,024 \text { lives lost. The need for } \\
\text { subdivision, it was stated "gathers momentum" but it was not until } 1929 \text { when a full International } \\
\text { Conference was convened to consider this matter. However, the system of subdivision devised falls } \\
\text { short of that agreed in 1913, evidence that IMO regulations reflect not experiential knowledge as it is } \\
\text { widely believed but the compromise reached in each convention. }\end{array}$ \\
\hline 1928 & $\begin{array}{l}\text { Loss of the Vestris inspired proposals at the SOLAS Conference in } 1930 \text { for more secure engine room } \\
\text { deck openings. }\end{array}$ \\
\hline 1929 & $\begin{array}{l}\text { United States ratifies the } 1929 \text { SOLAS Convention but only after the loss of the Mohawk by collision } \\
\text { and of Morro Castle by fire. }\end{array}$ \\
\hline 1948 & $\begin{array}{l}\text { Loss of the Sankey with all hands and the Flying Enterprise in } 1952 \text { inspired legislation to prevent } \\
\text { shifting cargoes. }\end{array}$ \\
\hline 1948 & $\begin{array}{l}\text { SOLAS Convention and the first specific criterion on residual stability standards with the requirement } \\
\text { for a minimum residual GM of } 0.05 \mathrm{~m} \text {. This represented an attempt to introduce a margin to } \\
\text { compensate for the upsetting environmental forces. }\end{array}$ \\
\hline 1954 & $\begin{array}{l}\text { Princess Victoria capsized and sank when large waves burst open the stern door in rough weather with } \\
\text { the car deck and starboard engine room flooding ( } 134 \text { died). }\end{array}$ \\
\hline 1955 & $\begin{array}{l}\text { Fire in the engine room of the Empire Windrush, with large loss of life, inspired the dispersal of fire } \\
\text { pump controls. }\end{array}$ \\
\hline 1956 & $\begin{array}{l}\text { The Andrea Doria built under SOLAS } 1948 \text { requirements, which were a slight improvement of the } \\
1929 \text { Conference capsizes in heavy seas and this alerts the profession to the fact that the effect of } \\
\text { waves on safety ought to be considered. This accident strongly influences proposals made to SOLAS } \\
1960 \text {. }\end{array}$ \\
\hline 1974 & $\begin{array}{l}\text { Straitsman capsized and sank whilst approaching its berth with its vehicle door partly open as a result } \\
\text { of squat, flooding the vehicle deck. }\end{array}$ \\
\hline 1974 & $\begin{array}{l}\text { IMO published Resolution A.2G5 (VIII) - regulations dealing with subdivision and damage stability } \\
\text { on a probabilistic basis - as equivalent to SOLAS deterministic rules. }\end{array}$ \\
\hline 1987 & $\begin{array}{l}\text { Herald of Free Enterprise capsized when the bow wave and bow-trim combined to bring the open bow } \\
\text { door underwater, flooding the vehicle deck. }\end{array}$ \\
\hline 1987 & $\begin{array}{l}\text { Santa Margarita Dos capsized in port in Venezuela due to heeling while loading vehicles as a result of } \\
\text { flooding of the vehicle deck. }\end{array}$ \\
\hline $\begin{array}{l}1987 / \\
1988\end{array}$ & $\begin{array}{l}\text { Following the Herald of Free Enterprise accident in } 1987 \text { with the loss of } 193 \text { lives and a public outcry, } \\
\text { SOLAS ' } 90 \text { came into effect for new ships build after 1990, introducing a considerable increase in } \\
\text { damage stability standards. Proposals by UK to phase-in upgrading of existing ships to SOLAS '90 } \\
\text { is rejected by IMO but a regional Agreement is reached by the North West European Nations. }\end{array}$ \\
\hline 1991 & $\begin{array}{l}\text { 1991: After a madman set fire on the Scandinavian Star causing the death of } 169 \text { people, retrospective } \\
\text { legislation was introduced for the first time in respect of enhanced "Structural Fire Protection". }\end{array}$ \\
\hline 1994 & $\begin{array}{l}\text { The Estonia is lost involving the loss of } 852 \text { lives. IMO rejects proposals for capability of withstanding } \\
\text { water on deck of Ro-Ro Passenger Ships. Regional agreement is reached ("Stockholm Agreement") } \\
\text { by the North West European Nations and later by the whole EU, Australia and Canada. }\end{array}$ \\
\hline
\end{tabular}




\begin{tabular}{|l|l|}
\hline 1995 & $\begin{array}{l}\text { In the 1995 SOLAS Diplomatic Conference SOLAS '90 is adopted as a global safety standard of } \\
\text { damage stability. A proposal to IMO of a new damage stability framework based on probabilistic } \\
\text { methods by the North West European Nations, following intensive research in the wake of Estonia } \\
\text { was tabled as an item for long term discussion. The proposal considers explicitly the effect of waves } \\
\text { and water on deck (performance-based criteria) deriving from the work undertaken by the Strathclyde } \\
\text { Stability Research Group and allows for various safety nets aiming to ensure that the Estonia disaster } \\
\text { will never happen again. A probabilistic framework was also developed and proposed, which formed } \\
\text { the foundation for the EU Project [HARDER (2003)], where the foundation of the probabilistic } \\
\text { regulations for damage stability was developed and brought to IMO, leading eventually to SOLAS } \\
\text { 2009. }\end{array}$ \\
\hline 2000 & $\begin{array}{l}\text { Express Samina: Flooding of the engine room and spreading of floodwater through open watertight } \\
\text { doors, leading to 81 fatalities. }\end{array}$ \\
\hline 2006 & $\begin{array}{l}\text { Al Salam Boccaccio '98: Following fire on the car deck, sprinklers were activated, which led to } \\
\text { floodwater being accumulated on the vehicle deck because of blocked freeing ports leading to the } \\
\text { vessel capsizing with 1,002 dead. }\end{array}$ \\
\hline 2012 & Costa Concordia: Side grounding damage, leading to up-flooding and capsize with 32 casualties. \\
\hline 2014 & $\begin{array}{l}\text { MV Sewol: Overloading/insufficient stability, leading to vessel listing heavily following a turn and } \\
\text { eventually capsizing with 295 casualties, mostly children. }\end{array}$ \\
\hline
\end{tabular}

Table 1: A Record of Flooding Disasters and Related Legislation

Notably, the development of a probabilistic damage stability framework in the late 1960s by [Wendel K. (1968)], leading eventually to A.165 Resolution in 1974, for such regulations to be considered as an alternative to the deterministic requirements, was in principle "put aside" but never forgotten. This "tortoise" pace of regulations development, primarily dictated by lack of understanding of the phenomena involved in flooding casualties, gave way to the steepest learning curve in the history of Naval Architecture, which continues unabated. Initially work has been funded post Herald of Free Enterprise by the UK Government, and the North West European Nations post Estonia. Subsequently, the EC took the mantle, starting with the introduction of performance-based standards and probabilistic damage stability regulations, brought to IMO with Project HARDER as the vehicle. The motivation and impetus to revive probabilistic regulations, in the quest for a more rational approach to damage stability and survivability post-Estonia, necessitated the development of appropriate methods, tools and techniques capable of meaningfully addressing the physical phenomena involved. Within 50 years, this quest has climaxed to the "zero tolerance" concept of Safe Return to Port, introduced in July 2009 and the ensuing developments pertaining to "Safety Level", "Alternative Design and Arrangements", "Risk-Based Design" and "Gold-Based Standards". This prompted an open proclamation by the then (April 2012) Secretary General of the International Maritime Organisation Koji Sekimizou, in addressing guests in the annual dinner of the Royal institution of Naval Architects, that deterministic requirements have no future. This has put ship safety in perspective and with flooding post collision and grounding accidents continuing to be the key risk contributor for passenger ships, resolving this problem remains a priority (Figure 1). In particular, for cruise ships, Figure 2 shows that the maximum numbers of passengers carried by the largest cruise ships each year has risen dramatically, almost doubling to 6,800 in 2019 compared to 1999 [Clarkson, 2020]. This means that there is now a far greater risk of passenger fatality from any given single accident.

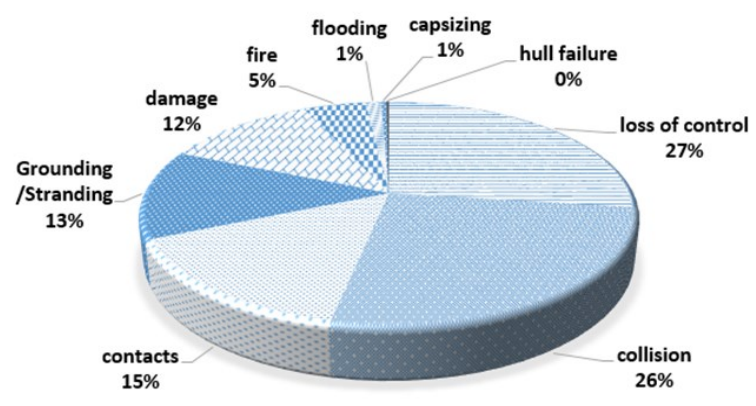

Figure 1: Casualty events for ships in the period 2011-2019

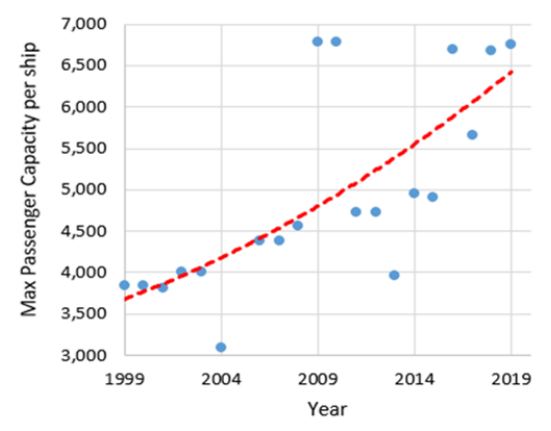

Figure 1: Capacities of largest passenger ships by year 
Moreover, the realisation that risk is inextricably linked to operation and a derivative of exposure has driven the industry to life-cycle considerations for effective risk management. This, in turn, has provided the motivation and the platform for wider industry inculcation. The author, having played a protagonist role in contemporary developments on damage stability and survivability and having been involved closely in implementing such developments to the design of modern megaships, will attempt to provide a succinct account of recent pertinent developments on damage stability and survivability and demonstrate their implications on passenger ship design and operation.

\section{Background}

From a basic Naval Architecture perspective, the most fundamental goal to be achieved is for a ship to remain afloat and upright, especially so after an accident involving water ingress and flooding. Regulations to address the former focus on subdivision and the latter on damage stability and survivability, even though more recent regulatory instruments tend to cater for both issues concurrently. As indicated at the introduction, with accidents providing the main motivation, emphasis has primarily been placed on reducing consequences, i.e., on cure rather than prevention. The key reason for this, derives from the fact that the residual risk post flooding accidents is unacceptably high, meaning that the most-cost-effective way to reducing flooding risk is to reduce the residual risk. The prevailing situation can be drastically improved through understanding of the underlying mechanisms leading to vessel loss and to identification of governing design and operational parameters to target flooding risk reduction cost-effectively. This, in turn, necessitates the development of appropriate methods, tools and techniques capable of meaningfully addressing the physical phenomena involved. Having said this, it was not until the 1990s when damage survivability, pertaining to ship dynamics in a damaged condition in a seaway, was addressed by simplified numerical models, [Vassalos, D. and Turan, O. (1992], [Vassalos, D., Turan, O (1994)]. [Vassalos, D., Letizia, L (1995)], [Kat, J de (1996)], [Zaraphonitis, G, Papanikolaou, A and Spanos, D (1997)].

As indicated in the introduction section, the subject of damage survivability in waves (with the ship hull breached), received particular attention following the tragic accident of Estonia, to the extent that this led to a step change in the way damage stability and survivability are being addressed, namely by assessing the performance of a vessel in a given environment and loading condition on the basis of first principles. In parallel, motivated by the compelling need to understand the impact of the then imminent introduction of probabilistic damage stability regulations on the design of cargo and passenger ships and the growing appreciation of deeply-embedded problems in both the rules and the harmonisation process itself, an in-depth evaluation and re-engineering of the whole probabilistic framework was launched through the EC-funded project [HARDER (2003)]. In this respect, the HARDER-project became an IMO vehicle carrying a major load of the regulation development process, fostering international collaboration at its best. This was a major factor, contributing to the eventual success in achieving harmonisation and in proposing a workable framework for damage stability calculations in IMO SLF 47. Deriving from developments at fundamental and applied levels in this project as well as other EC-funded projects, such as [NEREUS (1999-2002)], [ROROPROB (1999-2002)], SAFENVSHIP [Jasionowski, A (2005)], and other international collaborative efforts (work by the Stability in Waves Committee at the International Towing Tank Conference from 1996 onwards, e.g., [Jasionowski, A and Vassalos, D (2001)]), a clearer understanding of damage stability and survivability started to emerge. Application and verification of the developing numerical tools helped raise confidence in the available knowledge to address the subject matter effectively and with sufficient engineering accuracy. All this effort provided the inspiration and the foundation for the EC-funded large-scale Integrated Project [SAFEDOR (2005-2009)], which offered the opportunity to consolidate contemporary developments on damage survivability, thus rendering implementation possible even with severe time limitations, such as at concept design stage. The knowledge gained has been used to address critically contemporary regulatory instruments and to foster new and better methodologies to safeguard against known design deficiencies. This facilitated the evolution of safer designs, reflecting this knowledge, [Vassalos, D, York, A, Jasionowski, A, Kanerva, M and Scott, A (2006)].

However, the cultural "shock" of adopting probabilistic rules in the maritime industry has had a more profound effect. Surprisingly, the biggest influence has been seen at the birth place of prescription, namely IMO as indicated earlier, with goal-setting-performance-based approaches becoming the new face of safety. What is known as Safe Return to Port (SRtP) of SOLAS 2009, enforceable on every passenger newbuilding vessel and on special purpose 
ships over $120 \mathrm{~m}$ in length, has paved the way for holistic approaches to risk, specifically fire and flooding risks. These regulations represent a step change from the deterministic methods of assessing subdivision and damage stability. The old concepts of floodable length, criterion numeral, margin line, 1 and 2 compartment standards and the $\mathrm{B} / 5$ line have disappeared from newbuilding projects, which now adopt a more holistic approach to addressing damage stability and survivability. With some safety-minded ship owners, the possibility exists and it is being exploited to address and undertake design and operational measures to managing flooding risk, ranging from consideration of all conceivable (statistical, experiential, judgemental) damage scenarios, loading conditions and environments to deal with subdivision, damage survivability in waves and residual functionality of essential systems post-damage, including evacuation and rescue and decision support systems on board, targeting costeffective safety as a key design objective, alongside other conventional design objectives, [Vassalos, D (2012)]. With consideration of damage survivability analysis, using numerical time-domain simulation tools in newbuilding projects, the survivability of passenger ships, particularly cruise vessels has indicated considerable (positive) differences in comparison with SOLAS II-1, essentially static calculations, as indicated in Figure 3, [Atzampos, G (2019)]. The Direct Method indicates higher survivability for all cruise ship sizes by removing the need for conservative assumptions and irrational generalisations. In addition, they provide considerable additional valuable information for ship design and operation (especially extreme cases - emergencies).
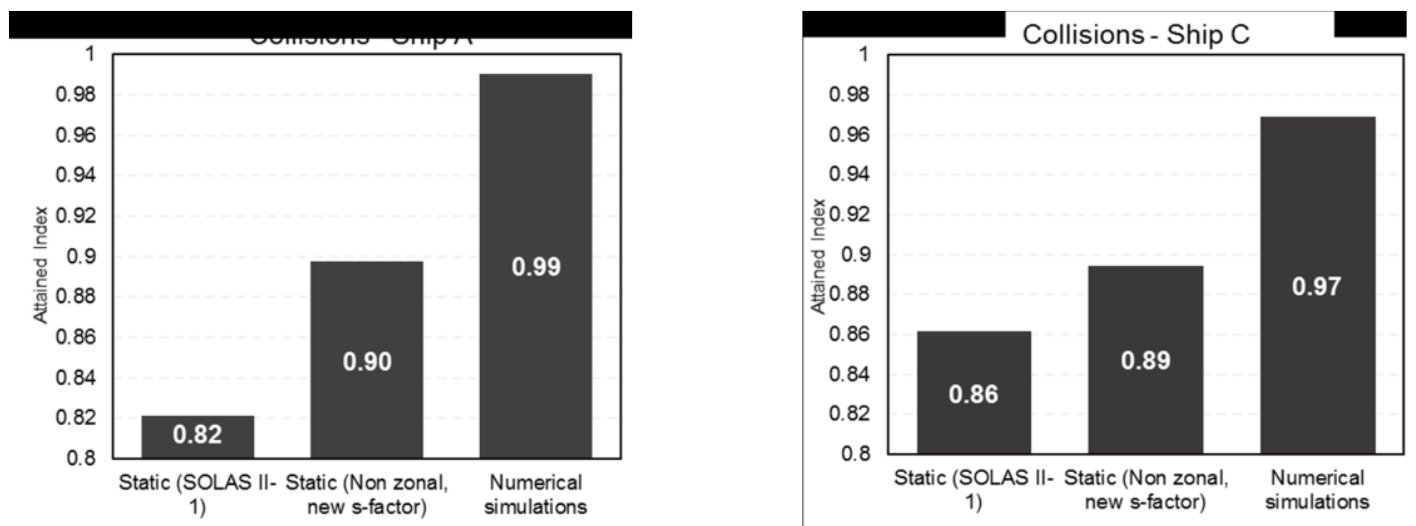

Figure 3: Comparison between SOLAS Damage Stability and Damage Survivability from Numerical Simulations

Notwithstanding the above, with probabilistic damage stability rules having originally been developed on the basis of cargo ship damage statistics, serious concerns have been raised regarding the adopted formulation for the calculation of the survival probability of passenger ships and the associated required subdivision indices, particularly for RoPax and large cruise ships, [Vassalos, D, Jasionowski, A, York, A and Tsakalakis, N (2008)]. Disquiet in industry and academia and concern deriving from the escalation of passenger ships to megaships, research focus on damage stability has shifted towards large passenger ships, [Vassalos, D and Jasionowski, A (2011)] and [Vassalos, D (2016)]. In this respect, a series of projects investigated this problem and laid down the foundation for a passenger ship-specific damage stability framework, process and criteria: [GOALDS (2009-2013)] and [Papanikolaou, A, Hamann, R, Lee, BS, Lemoine, L, Mains, C, Olufsen O, Tvedt, E, Vassalos, D and Zaraphonitis, G (2013)], [EMSA (2013-2015)], [EMSA (2009-2012)], [EMSA (2009-2012)], [eSAFE (2016-2018)], [DGMOVE (2017-2019)]. Becoming closer involved with passenger ships brought to light another important and material problem. Namely, in the quest for damage stability improvement, design (passive) measures have traditionally been the only means to achieve this in a measurable /auditable way (SOLAS 2009, Ch. II-1). However, in principle, the consequences from inadequate damage stability can also be reduced by operational (active) measures, which may be very effective in reducing loss of life (the residual risk). There are two reasons for this. The first relates to the traditional understanding that operational measures safeguard against erosion of the design safety envelop (increase of residual risk over time). The second derives from lack of measurement and verification of the risk reduction potential of any active measures. In simple terms, what is needed is the means to account for risk reduction by operational (interventional) means as well as measures that may be taken during emergencies. Such risk reduction may then be considered alongside risk reduction deriving from design measures. Therefore, new measures for risk reduction (operational and in emergencies) should be considered in addition to design measures. What needs to be demonstrated and justified is the level of risk reduction and a way to account 
for it, the latter by adopting a formal process and taking requisite steps to institutionalise it. Efforts in this direction has led to setting up a large scale EC-funded research Project, [FLARE, EU H2020 - MG2.2 (2019-2022)].

With monumental effort over the past three decades, the "quest" for providing a credible solution to the damage stability problem of ships (flooding risk) is within reach as outlined in the following. A brief account is first provided of the theoretical background and development of the requisite first-principles tools on damage stability and survivability in waves, leading to contemporary developments and implications on ship design and operation, including emergencies, and finishing with an implementation example in an attempt to demonstrate the level of consolidation of all these developments.

\section{Mathematical and Numerical Modelling of Ship Damage Stability and Survivability}

Even provision for initial static stability information, based upon inclining experiments to measure the metacentric height (GM), became mandatory for passenger ships as late as 1931. It is not surprising, therefore, to note that much more complex problems of dynamic ship stability and survivability in the presence of wind and waves attracted the interest of the profession only after mathematical models and computer technology, capable of handling the necessary excessive computations, became available in mid-20th century. However, the various techniques developed, which facilitated almost routine analyses for many fluid flow and dynamic phenomena pertinent to ship dynamics and safety, all focussed on ships in intact condition, [Vassalos, D. (2014)]. It was not until the 1980s and 90s that eventually one of the most difficult problems of dynamic stability pertaining to ships in a damaged condition, was addressed initially by simplified numerical modelling techniques, dealing with water on deck developed by [J. Dillingham, 1980] and the numerical model of damaged Ro-Ro vessel dynamic stability and survivability, [Vassalos, D. and Turan, O. (1992)]. Assessment of ship performance in terms of damage survivability in a seaway, however, is not a straightforward undertaking, as in addition to the complexity of predicting ship behaviour in waves, further intricate phenomena arise with water ingress-egress through the ship hull and the ensuing ship-floodwater-sea interaction and water sloshing, [Vassalos, D, Jasionowski, A (2002)]. This, in turn, depending on compartment geometry, dimensions and position with respect to the axis of rotation, amount of floodwater, and amplitude and frequency of motion [Van den Bosh, JJ and Vugts, JH], displays a behaviour ranging from small-amplitude short waves formation and non-linear standing waves to highly nonlinear hydraulic jumps or combinations of all these, [Hamlin, NA, Lou, YK, Maclean, WM, Seibold, F, Chandras, LM, (1986)]. The dynamic pressures exerted on the compartment walls are also of non-linear nature as they comprise both non-impulsive loads related to fluid transfer as well as impulsive localised loading. Such dynamic effects of fluid motion on the ship response, and vice-versa, have been extensively studied since the late $60 \mathrm{~s}$ mostly from the viewpoint of roll stabilising tanks, water trapped on deck, LNG carriers and related problems where the amount of fluid mass in the tank is constant. However, the problem of a ship undergoing progressive flooding entails further degrees of freedom and complexity arising from fluid mass variation, which also renders all related processes non-stationary, (see, for example, Figures 4 and 5, [FLARE, EU H2020 - MG2.2 (20192022)]).

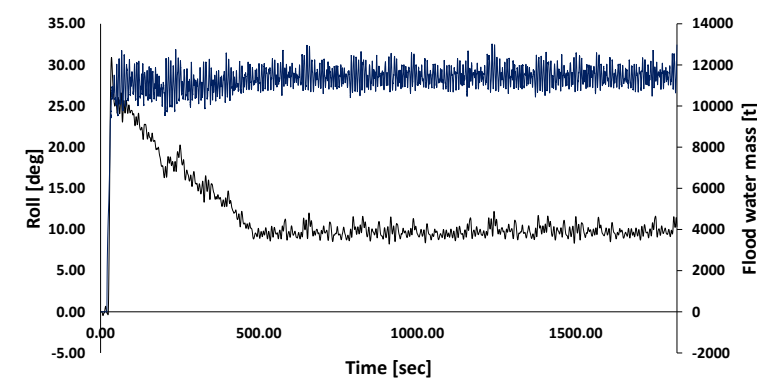

Figure 4: Damaged cruise ship dynamics in random waves - Large transient response $>30$ degrees, subsequent progressive flooding and stationary state state.

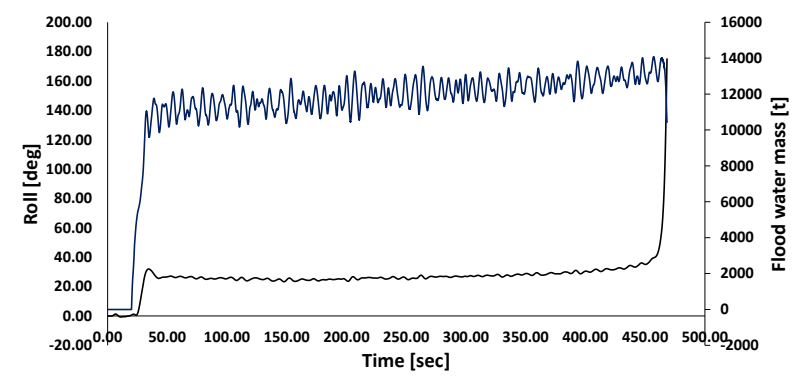

Figure 5: Damaged cruise ship dynamics in random waves - Large transient response $>30$ degrees, followed by progressive flooding and ultimately vessel loss.

Published research on the subject exhibits tremendous variety in levels of sophistication and type of approaches used to solving these problems. Two approaches can be broadly distinguished: (a) simplified 
numerical methods based on rigid-body theory and using a Bernoulli-based mechanism for modelling water ingress-egress, for example the work by [de Veer, de Kat Jan (2000)] and (b) techniques employing Computational Fluid Dynamics (CFD), in which the excited due to tank/ship motion internal fluid behaviour is dealt with by coupling the solution of RANS equations with the simultaneous time-domain solution of equations of intact ship motions, treating the fluid forces as external input, for example [Gao, Z, Vassalos, D and Gao, Q (2010)] and [Gao, Z (2012)] where physical and numerical experiments were undertaken. Interestingly, [Woodburn, Letizia, Gallagher (2002)], modelled the water ingress/egress and damaged ship dynamics whilst allowing for direct coupling between external and internal fluid domains via a water column, Figure 6. A more recent treatment using CFD is reported by [Eivind R, et al (2019)], with a snap shot of the process shown in Figure 7.

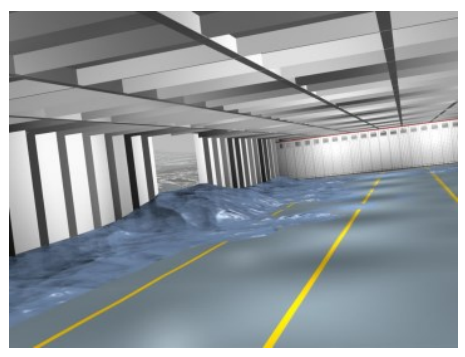

Figure 6: Coupling between sea-ship-floodwater responses, [Woodburn, Letizia, Gallagher (2002)]

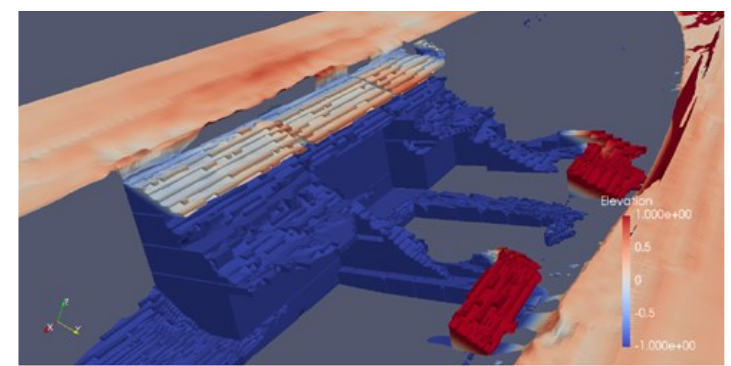

Figure 7: Snap shot of trnasient flooding in a ship compartment [Eivind R, et al (2019)]

More methodological treatment of such tools, leading to knowledge intensive models (for example. response surfaces) are paving the way, starting as far back as early 2000s, for example in the EC-funded IP project [VIRTUE $(2005,2009)]$. Other than some gains attributable to higher computing power, for example, for example [Zhang X, Lin, Z, Mancini S, Li P, Li, Z and Liu, F (2019)], no significant advance is noted in this direction as concluded in the Joint Industry Project [eSAFE (2016-2018)]. Such numerical treatment of damage stability is deemed to evolve into a viable alternative to physical model testing, once fuller understanding of the overly complex processes involved is gained and reliable methods for modelling this become adequately validated and accessible. This forms part of [FLARE, EU H2020 - MG2.2 (2019-2022)], where in addition to validaing numerical tools for routine evaluation of damage stability and survivability in waves, high fidelity numerical tools will also be utilised for verificatioon and valaidation of the numerical tools that will eb used routinely in the design process.

The next session sets to discuss various aspects of the modelling of the dynamic behaviour of a damaged ship, by summarising the research efforts of the last 30 years, with a threefold purpose: firstly, to illustrate the suitability of simplified techniques for representing the behaviour of damaged ships; secondly, to demonstrate the practical use of this kind of numerical models; thirdly, to highlight the difficulties and knowledge gaps on various aspects remaining unresolved to date and, therefore, underline the need for on-going concerted research efforts on damage ship stability and survivability, one such example being the large-scale EU-funded Project [FLARE, EU H2020 - MG2.2 (2019-2022)].

\section{Damaged Ship Dynamics in a Seaway}

\subsection{Damaged Ship Motions}

The primary objective for passenger vessels (indeed, any vessel) is to ensure that, in case of a flooding accident, the vessel will remain upright and afloat, certianly for sufficient time to ensure that passengers and crew sre safely evacuated. Therefore, it is essential to model accurately the vessel behaviour post-accident events. This, however, as indicated in the foregoing is a very complicated process, involving highly non-linear transient phenomena and in cruise ships complicated internal envirnments. In the latter, the influence of even small changes in some of the parameters playing a part in determining the sequence of events taking place during the flooding process, could lead to completely different end results concerning capsize ot not capsize and the time that it takes in the latter case (Time to Capsize). Therefore, static stability calculations for a damaged vessel undergoing 
flooding in a seaway may give a completely misleading impression of her dynamic behaviour and outcome [Letizia, L (1996)]. Therefore, in order to tackle damage ship dynamics, it is necessary to develop a time-domain numerical prediction tool for simulating ship behaviour whilst accounting for progressive flooding. Such numerical treatment of damaged ship dymaics is deemed to evolve into a viable alternative of physical model testing, once fuller understanding of the overly complex processes involved in ship capsize/sinking is gained and reliable methods for modelling these phenomena become adequately validated. Henceforth, by achieving widespread utilisation in routine design practices, such tools would contribute significantly to ship safety improvement, as by enabling systematic identification of stability deficiencies and survivability assessment, they would allow safety to become an inherent feature of new designs, indeed for safety (damage stability) to be treated as a design objective, as well as a ltfe-cycle imperative, [Vassaos, (2014)].

The approach that has been folowed originally, namely in the early 1990s, and has attracted considerable research interest over the recent past, is based on rigid body dynamics, aiming at achieving a balance between simplicity and meaningful representation of physics. Here, the mass of floodwater in the ship hull is treated as a pendulum attached to the ship, with its mass located at the centre of the fluid volume, which in turn is found from the intersection between compartment geometry and fluid free surface, the latter assumed to be flat. The fluid free surface is either assumed to remain parallel to the sea level, e.g. [Vassalos, Turan (1994)], [Vassalos, Letizia (1995)], [de Kat (1996)] or to be moving in accordance with some basic motion mechanism, e.g. [Zaraphonitis, Papanikolaou, Spanos (1997)], [Papanikolaou, Zaraphonitis (2000)] and [Jasionowski (2001)]. This section offers a brief overview of the mathematical model deriving from this approach, including the generalised ship motions and the floodwater motion mechanism, as described in [Vassalos, D. (2014)] but accounting for recent progress with some discussion and focus on issues remaining unresolved. Equations describing damaged ship behaviour are derived from fundamental motion principles: the law of conservation of linear and angular momentum. This law, normally applied to rigid bodies, is here also extended to the internal fluid mass, resolved in a body-fixed system of reference, as shown in Figure 8. Rigorous derivation leads to a set of 6 scalar equations for linear and angular motions. Of these, the three equations for angular motions are presented here in vector form (1). For a detailed explanation of all the relevant terms and of the model itself, see [Jasionowski (2001)].

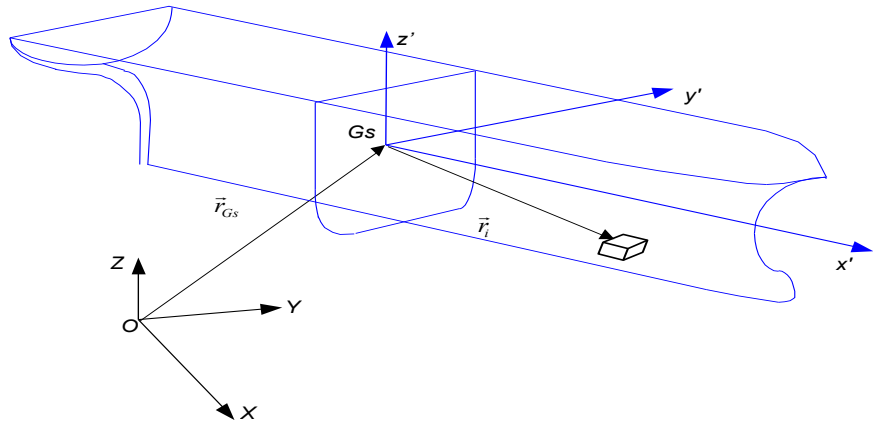

Figure 8: Coordinate system fixed to the centre of gravity of the intact vessel

$$
\begin{gathered}
\left(I_{s}^{\prime}+I_{w}^{\prime}\right) \cdot \frac{d}{d t} \vec{\omega}^{\prime}+M_{w} \cdot\left[\vec{r}_{w}^{\prime} \times\left[\frac{d}{d t} \vec{v}_{G s}^{\prime}\right]\right]+ \\
+M_{w} \cdot\left[\left(\vec{\omega}^{\prime} \times \vec{r}^{\prime}{ }_{w}\right) \times \vec{v}^{\prime}{ }_{w}\right]+ \\
+M_{w} \cdot\left[\vec{r}_{w}^{\prime} \times\left[\frac{d}{d t} \vec{v}^{\prime}{ }_{w}+\vec{\omega}^{\prime} \times\left(\vec{v}_{G s}^{\prime}+\vec{v}^{\prime}{ }_{w}\right)\right]\right]+ \\
+\frac{d}{d t} M_{w} \cdot\left[\vec{r}^{\prime}{ }_{w} \times\left(\vec{v}_{G s}^{\prime}+\vec{v}_{w}{ }_{w}\right)\right]+ \\
+\left(\frac{d}{d t} I^{\prime}{ }_{w}\right) \cdot \vec{\omega}^{\prime}+\vec{\omega}^{\prime} \times\left[\left(I^{\prime}{ }_{s}+I^{\prime}{ }_{w}\right) \cdot \vec{\omega}^{\prime}\right]=\vec{M}_{G s}^{\prime}
\end{gathered}
$$


The right hand side of the equation, $\vec{M}_{G s}^{\prime}$, and the respective force vector $\vec{F}$ of the rectilinear motions, represent all the external forces and moments acting on the vessel, expressed in a body-fixed system of reference, Gsxyz, located at the ship centre of mass. These forces/moments are predicted with conventional fluid dymamics models as applied in Naval Architecture over the past half-century. The Froude-Krylov and restoring forces and moments are integrated up to the instantaneous wave elevation. The radiation and diffraction forces and moments are derived from linear potential theory and expressed in time domain using convolution and spectral techniques, respectively. The hull asymmetry due to floodwater is taken into account by a "database" approach, whereby the hydrodynamic coefficients are predicted beforehand as function of sinkage (draft), heel and trim and interpolated during the simulation accounting for floodwater accumulation and progression, as illustrated in Figure 9. Figure 10 illustrates a RANS-based estimation of the inertia coefficients for a 2D model the same vessei.

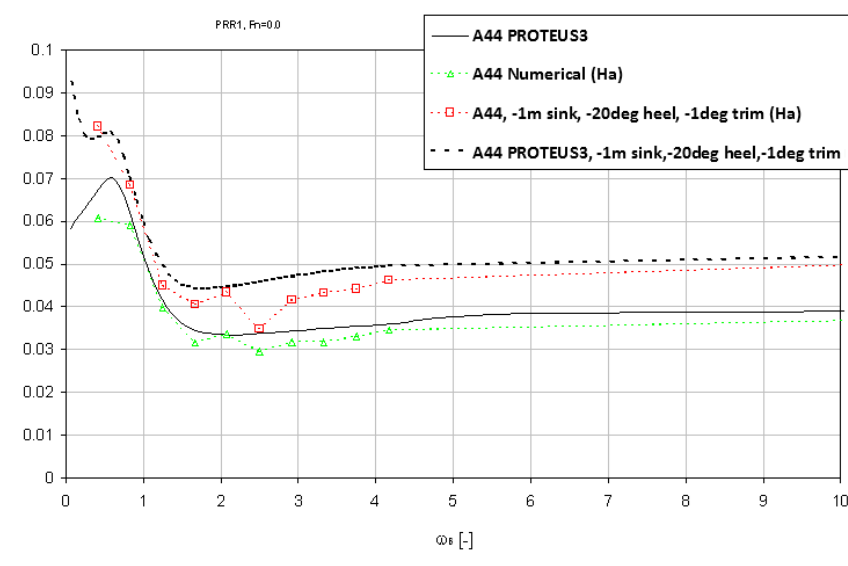

Figure 9: Dimensionless roll added moment for 3D PRR1 hull form; effect of $-1 \mathrm{~m}$ sinkage, 20deg heel and $-1 \mathrm{deg}$ (aft) trim, derived by strip theory and $3 \mathrm{D}$ panel methods at $\mathrm{Fn}=0.0$, Project [HARDER (2003)].

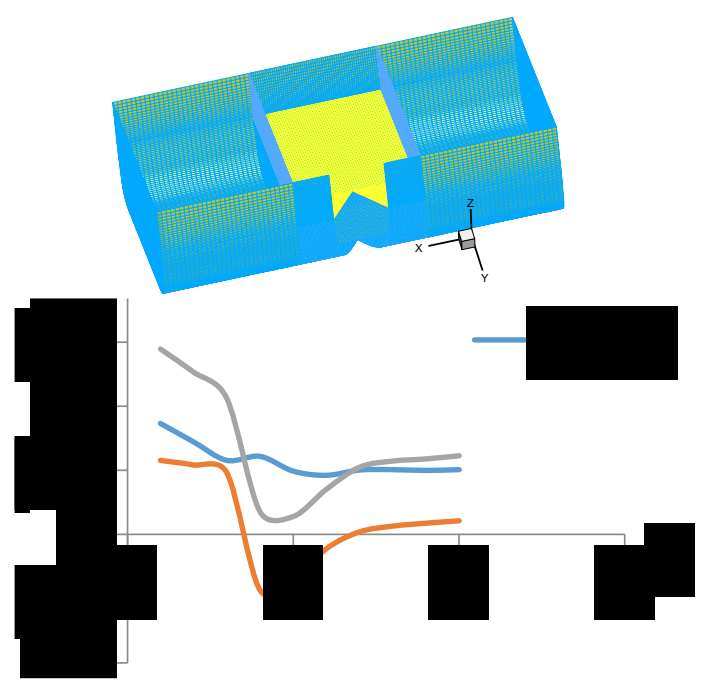

Figure10: Bergandy 2D Model Surface Mesh snd Sdded Inertia Coefficients [Gao, Q (2012)].

The second order drift forces, wind and current effects and other forces of viscous origin are also catered for, based on parametric formulations. Naturally, the gravity force and moment vectors correspond to ship and floodwater weights.

$$
\begin{gathered}
\vec{F}, \vec{M}_{G s}^{\prime}=\vec{F}_{\text {Gravity }}+\vec{F}_{F-K, \text { Restoring }}+\vec{F}_{\text {Radiation }}+\vec{F}_{\text {Diffraction }} \\
+\vec{F}_{\text {ManouvringRudder }}+\vec{F}_{\text {Drift,Current, Wind,Viscous }}
\end{gathered}
$$

Where:

$\vec{F}_{\text {Restoring }} \vec{F}_{F-K}$

$\vec{F}_{\text {Radiation }}$

$\vec{F}_{\text {Diffraction }}$

$\vec{F}_{\text {Manoeuvrig,Rudder }}$

$\vec{F}_{\text {Drift,Current, Wind,Viscous }}$
Direct integration of static pressures on actual geometry

Convolution techniques

Spectral techniques

Empirical formulae

Empirical formulae

A correction for viscous effects on roll motion is applied based on an established empirical method proposed in [Himeno, Y (1981)], where the viscous damping moment is divided into several components: friction, eddy shedding, lift, wave and bilge keel and the total force is obtained by superposition of all these components. 
However, the proposed method, representing the non-linear viscous damping as an equivalent linear coefficient at the roll natural frequency, remains a function of roll amplitude, which cannot be known a priori and hence not

suitable for application to time-domain simulation in random seas. In this respect, an engineering approximation has been proposed in [Vassalos and Turan (1992)], whereby a discrete piece-wise constant treatment of the linearised coefficient is used with the coefficient evaluated at the wave spectrum peak frequency and for an amplitude corresponding to the amplitude of the last half-roll cycle. In this approach, the viscous roll damping will vary with time, constantly adjusting as afunction of roll amplitude.

The whole system (1), after re-arranging into a matrix form as a set of twelve differential equations of the first order, is solved for position in space of the centre of gravity of the intact ship (3) and three rotations through a 4th order Runge-Kutta-Feldberg integration scheme with variable step size.

$$
\vec{r}_{G s}=\int \vec{v}_{G s} \cdot d t
$$

\subsection{Internal Sloshing Model}

Still undetermined in equations (1), are the relevant vectors for floodwater location, velocity and acceleration, ${ }^{{ }^{\prime}}{ }_{w}, \vec{v}^{\prime}{ }_{w}$ and $\frac{d}{d t} \vec{v}^{\prime}{ }_{w}$, respectively. These are the quantities that must be derived from a model representing the sloshing water phenomenon. When CFD techniques are used, these vectors and related forces and moments can be derived from integration of pressure due to fluid motion. Here, however, see Figure 11, the simplification mentioned in the foregoing, is adopted.

$$
\left\{\begin{array}{l}
\frac{d}{d t} \vec{r}_{w}^{\prime}=\vec{v}_{w}^{\prime}-\left(\vec{v}_{w}^{\prime} \cdot \vec{n}^{\prime}\right) \cdot \vec{n}^{\prime} \\
\frac{d}{d t} \vec{v}_{w}^{\prime}=\vec{a}_{f}^{\prime}-\left(\vec{a}_{f}^{\prime} \cdot \vec{n}^{\prime}\right) \cdot \vec{n}^{\prime}
\end{array}\right.
$$

A lumped mass model, the initial concept of which was presented by [Papanikolaou, Zaraphonitis et al: (2000)], has been developed treating the floodwater as a free point-mass moving due to the acceleration field and restrained geometrically by predetermined potential surfaces of the centre of buoyancy for given amounts of floodwater, FMPS (Free Mass in Potential Surface), as shown in Figure 11 and Figure 12. This model, derived from simple rigid body motion consideration, similar to that leading to equations (1), is presented as a set of equations (4), with graphical explanation provided in Figure 11.

The total forcing acceleration vector is: $\quad \vec{a}_{f}^{\prime}=\vec{g}^{\prime}-\vec{a}_{s}^{\prime}-2 \cdot \vec{\omega}^{\prime} \times \vec{v}^{\prime}{ }_{w}-\mu^{*} \cdot \vec{v}^{\prime}{ }_{w}$

Where $\vec{a}_{s}$, see equation (6), is a ship motion-related acceleration vector expressed in a body-fixed system of reference.

$$
\vec{a}_{S}^{\prime}=\frac{d}{d t} \vec{v}_{G s}^{\prime}+\frac{d}{d t} \vec{\omega}^{\prime} \times \vec{r}^{\prime}{ }_{w}+\vec{\omega}^{\prime} \times\left(\vec{v}_{G s}^{\prime}+\vec{\omega}^{\prime} \times \vec{r}^{\prime}{ }_{w}\right)
$$




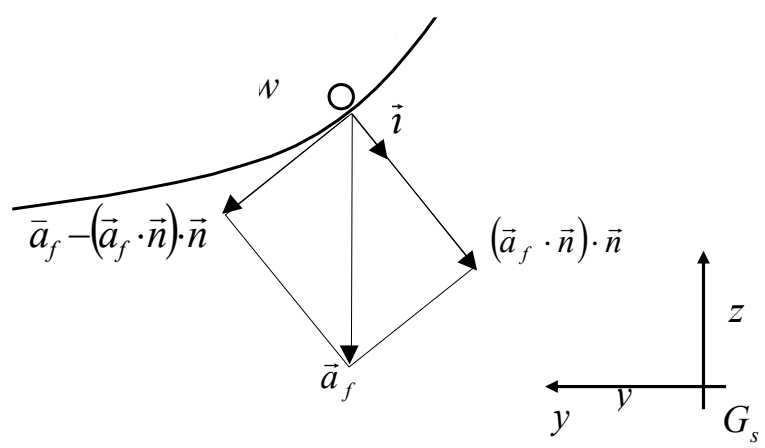

Figure 11. Fluid particle "w" (centre of buoyancy) in acceleration field $\vec{a}_{f}$ moving on the potential surface S; all vectors are resolved in the Gsxyz system of reference.

$\vec{n}$ is the instantaneous normal vector to the potential surface of floodwater motion, determined from a damage compartment geometry database. Note that the vector is a function of $\vec{r}_{w}$ and volume of the fluid. Finally, $\mu^{*}$ is an artificial coefficient, introduced to represent damping of floodwater motion. This coefficient is assigned an adhoc value derived from experimental data using a simple box-shaped compartment, [Van den Bosh, JJ and Vugts, $\mathrm{JH}$ (1966)]. With the geometric information concerning the tank stored in a database, such as shown in Figure 12 and Figure 13, the model is complete. Equation (4) is set up for each flooded compartment within the ship and solved simultaneously with the equations for ship motion. Having determined fluid motion, the forces and moments due to its displacement can be calculated. For demonstration purposes, the moment vector extracted from equation (1) is used and presented in the form of equation (7), where three components are distinguished, representing inertial, gravity and non-linear effects and shown in equations (8), (9) and (10), respectively. Note here that the fluid inertia matrix, $I^{\prime}{ }_{w}$, contains only the inertia of a single point-mass located at position $\vec{r}^{\prime}{ }_{w}$ in the ship-fixed system of reference at Gs. Since the mass is constant, the terms containing the time derivative of the mass, will vanish.

$$
\vec{M}^{\prime}{ }_{w a t}=\vec{M}_{I}^{\prime}+\vec{M}_{g}^{\prime}+\vec{M}_{N}^{\prime}
$$

Where,

$$
\begin{aligned}
& \vec{M}_{I}^{\prime}=I_{w}^{\prime} \cdot \frac{d}{d t} \vec{\omega}^{\prime} \\
& \vec{M}_{g}^{\prime}=M_{w} \cdot \vec{r}^{\prime}{ }_{w} \times \vec{g}^{\prime}
\end{aligned}
$$



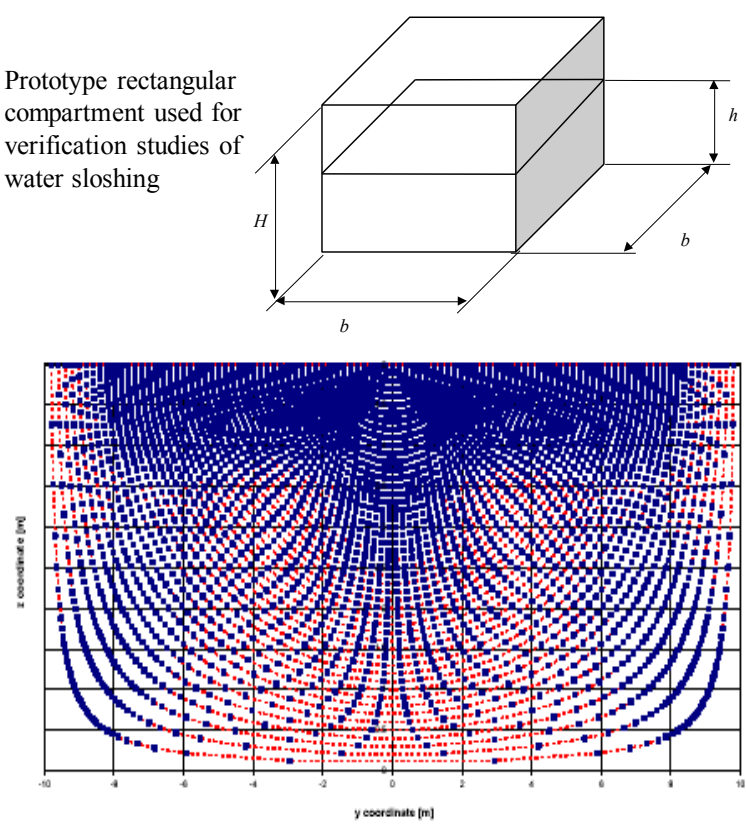

Figure 12: Description of geometric constraints for motion of centre of buoyancy of floodwater.
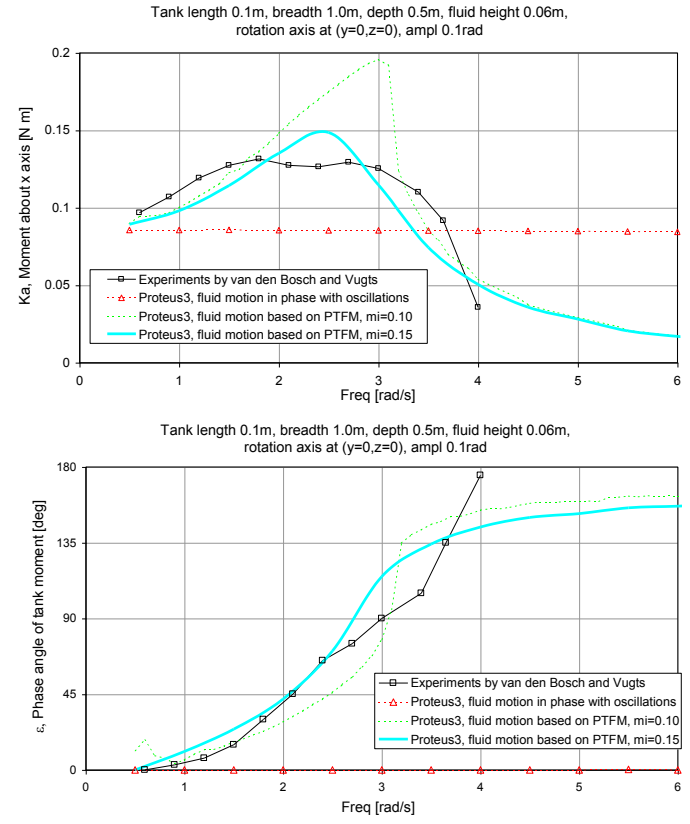

Figure 13: Comparison of fluid moment amplitudes and phase angles derived by experiments and in-phase FMPS sloshing models.

\subsection{Floodwater Ingress/Egress, Progression and Accummulation}

Water ingress/egress and the ensuing floodwater progression and accummualtion within the ship internal environemnt affects the dynamics and the fate of a damaged ship in two distinct ways: firstly, the influence on ship hydrodynamics and through coupling of floodwater dynamics with ship dynamics the overall dynamic behaviour; secondly, and the most considerable consequence of flooding in a typical passenger ship, is vessel capsize or sinking as a result of water accumulation (see flooding loss modalities in the next section).

Therefore, modelling this element should be performed to the highest accuracy attainable. However, knowledge on the mechanics of water flow through the damage opening of a moving ship in the presence of incident, diffracted and radiated waves, is very complex. Therefore, the fundamental Bernoulli fluid momentum equation is used most commonly (as depicted in Figure 14), with all the unknown flow physics encapsulated in a single averaged flow loss coefficient $\mathrm{K}$, which is derived from experiments (e.g., Figure 15).
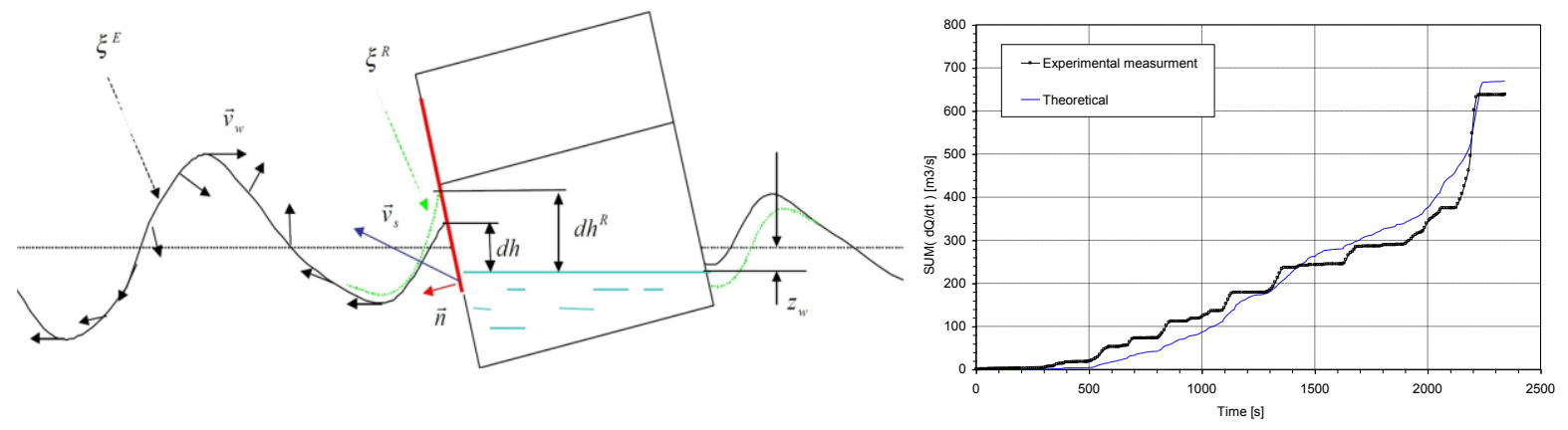

Figure 14: Simplified modelling of water ingress/egress

Figure 15: Comparison between experimental measurements and theoretical predictions of water accumulation.

$$
Q=K \cdot A \cdot \int_{t} \sqrt{2 \cdot g \cdot d h} \cdot d t
$$


Where,

$\mathrm{K}$

Flow loss coefficient

A Submerged area of damage opening

Although this model can prove accurate in many cases, as demonstrated in Figure 15, by no means does it resolve the problem of not knowing the instantaneous water ingress/egress in case of marginal survivability. This has direct impact on the accuracy of estimations of how long it takes a vessel to sustain the action of waves whilst undergoing progressive flooding that leads to eventual capsize (time to capsize). Significant contributions in this particular subject have been made by the EC-funded Project [FLOODSTAND, (2009-2012)] as reported by [Ruponen, P,, Kurvinen, P, Saisto, I and, Harras, J (2013)] and more latterly by [Jalonen, R, Ruponen, P, Weryk, M, Naar, H and Vaher, S (2017)].

Considering the subtlety of regulations, such as SRtP, but also estimation of flooding risk in general, the accuracy of predictions of ship survivability including the time it takes for a vessel to capsize from the instant the hull is breached, is paramount. Therefore, water ingress/egress will have to be considered as one of the major factors, the accuracy of prediction of which will determine the robustness of the whole damaged ship dynamics model. Achieveing adequate accuracy in our predicitions of this particular phase of flooding is one of the key objectives in Project FLARE, [FLARE, EU H2020 - MG2.2 (2019-2022)].

\subsection{Hydrodynamic Reaction Forces/Moments of a Damaged Ship}

How to meaningfully model the influence of floodwater on ship hydrodynamics and the coupling of floodwater dynamics into ship dynamics is still in need of focussed attention. To this end, some experimental studies have been undertaken using scale models of typical modern passenger ships, in this specific case a Ro-Ro vessel [Cichowicz, J, Jasionowski, A and Vassalos, D (2010)], aiming to qualify and quantify the level of contribution of hull damage and the ensuing flooding process to the overall ship hydrodynamic properties.

In this particular case, forced oscillations are considered of the model in damaged conditions in various degrees of freedom with the use of purposely-designed mechanical forcing systems, such as shown in Figure 16 and Figure 17.

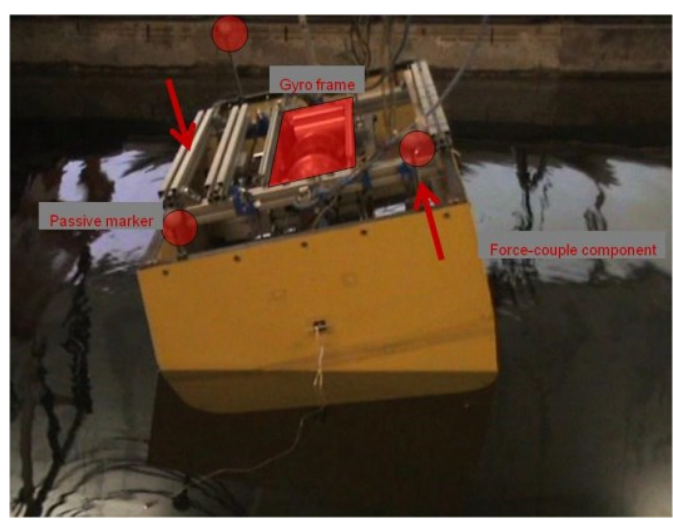

Figure 16: Experiments - Arrangements for forced oscillations of a free-floating RoPax section

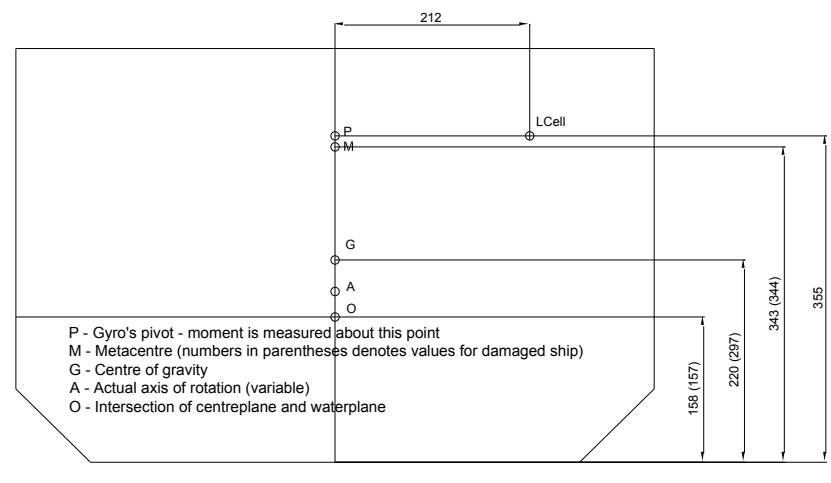

Figure 17: Experiments - Geometrical data

The derived results have been compared with predictions using well-established numerical techniques leading to the general conclusion that whilst the effect of hull damage on hydrodynamic forces in heave is negligible, the corresponding effect in roll is considerable, as shown in Figure 18. Estimation of the coefficients was carried out based on time series of the force signals and a least squares fit assuming that the two pertinent moments (added moment and damping) are orthogonal and independent (this, in itself is an assumption that needs further investigation). 


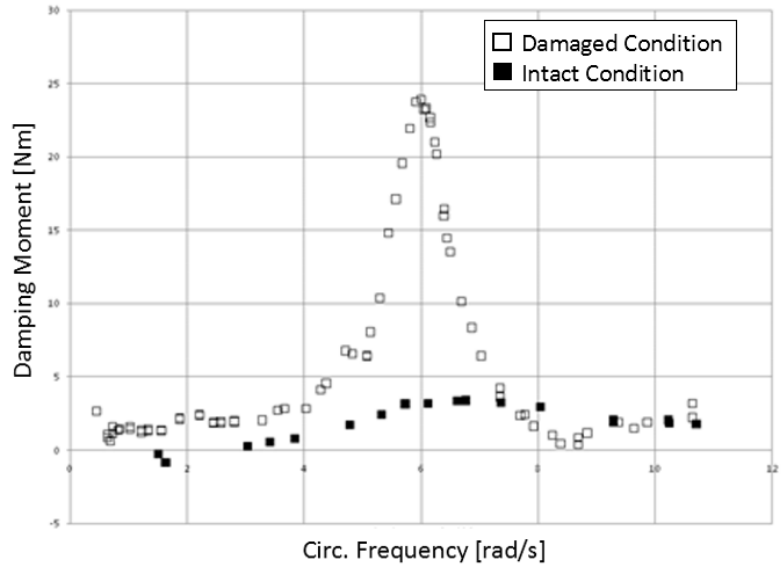

Roll Damping Moment

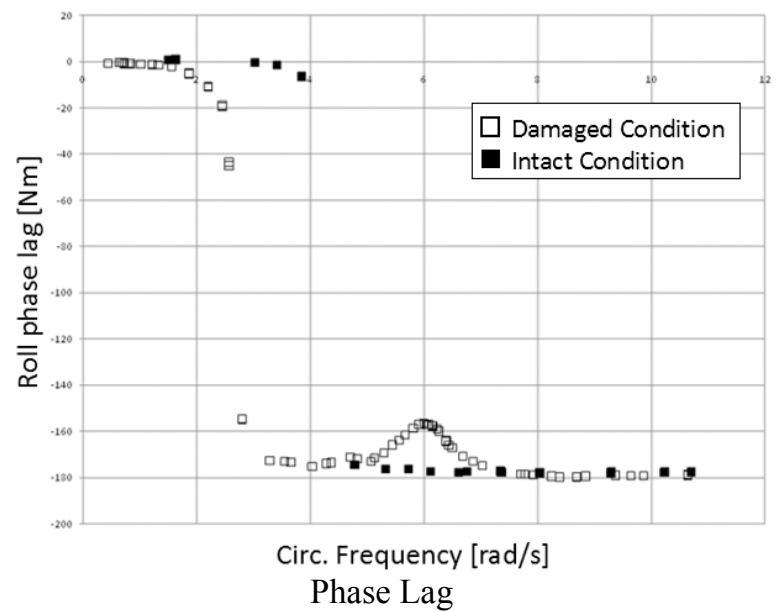

Phase Lag

Figure 18. Measured characteristics of roll damping moment and phase lag in intact and damaged conditions

In this respect, it is worth emphasising that it is not clear to what extent, if at all, such orthogonal decomposition of these effects is valid, as the water ingress and egress and ensuing effects on ship hydrodynamics and floodwater dynamics are of strongly non-linear character. Therefore, they could be neither in phase with velocity nor acceleration of ship motion. Hence, the exact nature of the effects of flooding is not known. The main aim of this investigation was to qualitatively assess the nature and scale of the effects of hull damage and ensuing flooding on ship hydrodynamics and ship motions, with further rigorous study to quantify these effects left for future work. Nevertheless, the work carried out clearly demonstrates that floodwater motions have a major impact on damping. As shown in Figure 18, with the excitation frequency approaching sloshing natural frequency, the hull and floodwater oscillations are out of phase (and in the presence of the damage opening a significant drift, $1.3 \mathrm{~m} / \mathrm{s}$ full scale, is observed), which results in a large "dip" in the roll motion phase characteristics. Bearing in mind that the amplitude response is virtually unaffected, this causes a substantial increase of damping (note also that the frequency shift in phase angle between intact and damaged condition is a consequence of the difference in the dry hull KG resulting from maintaining the same draught in both conditions). In fact, the tenfold increase of the roll damping moment cannot be solely associated with the "inappropriate" mathematical model used in the analysis of the experimental results and is indicative of the escalation in the fluid reaction forces/moments for a damaged ship in waves. Specific experiments to address further these issues are being undertaken in Project FLARE, [FLARE, EC H2020 - MG2.2 (2019-2022)].

\subsection{Loss Modalities of a Damaged Ship}

Following hull breach of a ship in a seaway that leads to flooding of internal ship spaces, the ship will undergo a transient response as a result of the inrush of floodwater, which may lead to the vessel capsizing without equilibrium being restored (transient asymmetric flooding), Figure 19. This transient capsize phenomenon was first noticed and studied in [Vassalos, D, Jasionowski, A and Guarin, L (2005)] but the observations and derived results did not make any significant inroads into IMO. 


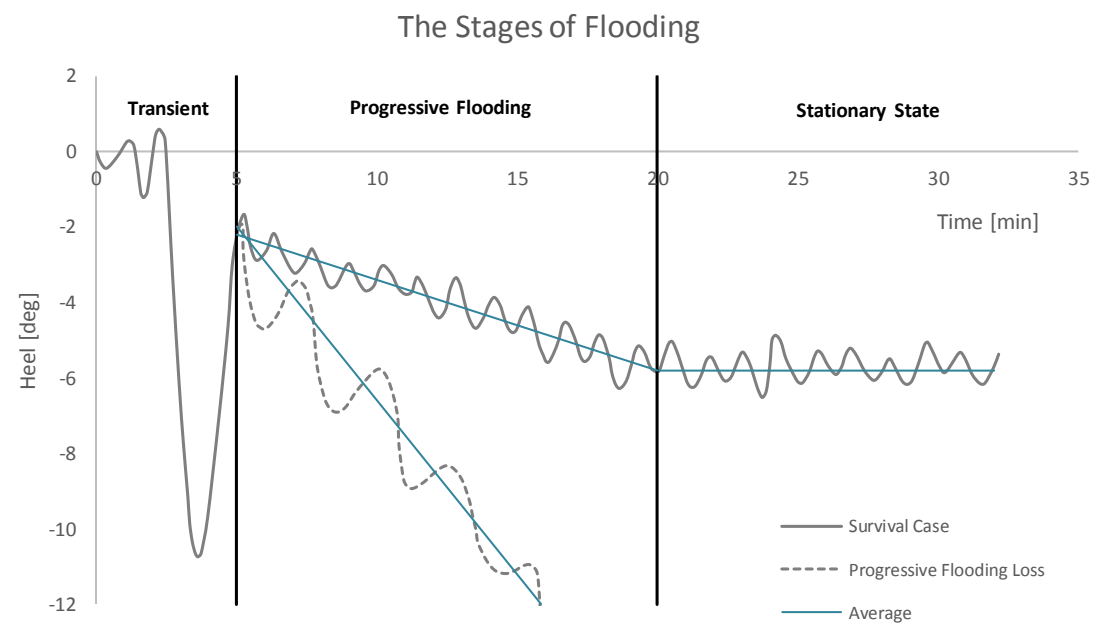

Figure 19: Loss modalities of a damaged ship

Transient State: Inrush of water through hull breach, causing rapid large heel into/away from breach side, in a time interval shorter than the natural period of the ship.

Progressive State: Stage in which floodwater propagates through unprotected openings within the vessel, slowly diminishing stability until either a stationary state is reached or the vessel succumbs to capsize/sinking; general duration from several minutes to hours.

Stationary State: The vessel reaches some form of quasi-dynamic equilibrium (average roll is constant).

This is rather unfortunate, as time limitations, relating to transient flooding loss, render this the most dangerous loss mode. Some attempts have been made to consider the effect of transient flooding on stability by focusing on different stages of this process in a quasi-static manner and, in this respect, an intermediate stage sfactor has been adopted at IMO (SOLAS 2009 Regulations) as shown in (12). However, this is too large an approximation, thus hiding the problem more often than not.

$$
S_{\text {intermediate }, i}=\left[\frac{G Z_{\max }}{0.05} \cdot \frac{\text { Range }}{7}\right]^{\frac{1}{4}}
$$

Figure 19, relating to a large-scale model experiment and to numerical simulation results of the same, demonstrate that transient capsize of a typical cruise ship 2-compartment SOLAS damage could take place rather quickly for a ship in full compliance with statutory damge stability regulations, [Vassalos, D, Jasionowski, A and Guarin, L (2005)].

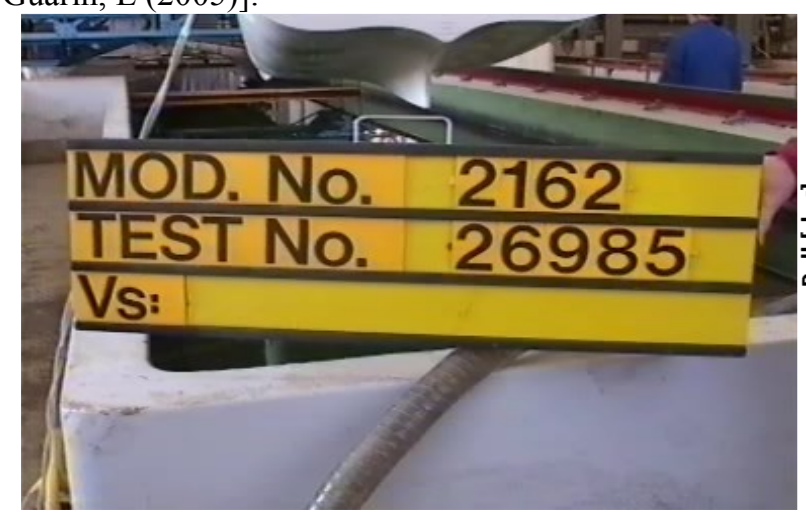

(a)

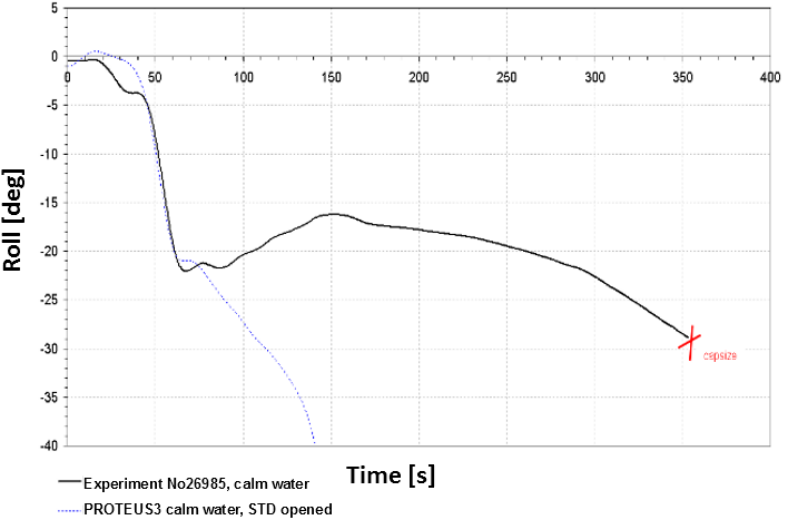

(b)

Figure 20. Typical transient loss modality distribution for a SOLAS'90 cruise ship (model experiment and numerical simulation results) 
Similarly Figure 21, where time-domain simulation software is used to to identify different loss modalities, demonstrates that transient capsizes for 2-comprtment damages of a very good SOLAS '90 cruise ship design is quite common.

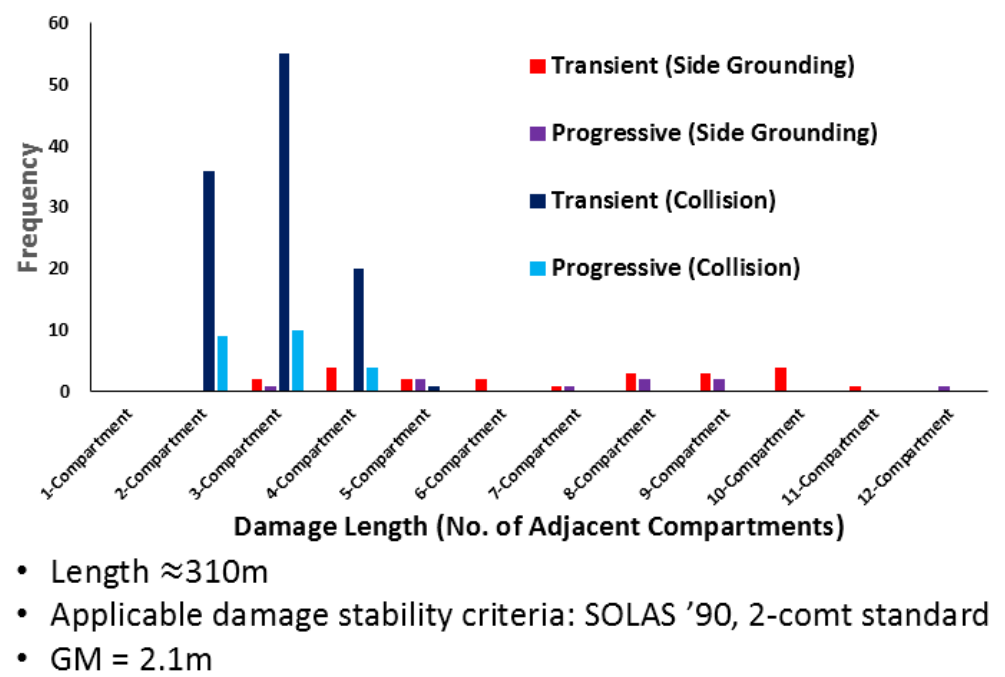

Figure 21: Typical loss modality distribution for a SOLAS'90 cruise ship

Progressive flooding capsizes have been studied more systematically in the various EC-funded and other projects mentioned in the foregoing and have been made the basis for the current SOLAS (SOLAS 2009 and SOLAS 2020) requirements. However, even in these regulations, this loss modality is considered on the basis of mainly experimental results of RoPax vessels in waves up to $4 \mathrm{~m} \mathrm{Hs}$ with the effect of the latter considered as an average influence on survivability, captured by correlating GZ-curve properties (GZmax and Range) to Hs. Typical RoPax vessel test set up and results in progressive flooding loss modality are shown in Figures 22 and Figure 23, respectively. This is a mode of capsize that was made the basis for all contemporary developments, particularly pertaining to probabilistic regulations, adopted at IMO. The rapidly escalating trace of waer on deck in Figure 23 designates the time instant, which is normally referred to in the litterature as the "point of no return" at which the mass of floodwater on the car deck increases exponentially and the vessel capsizes very rapidly.

Of course, in the presence of superstructure, this may delay considerably as in the case of the RoPax vessel Estonia where it has taken 50 minutes for the vessel to "turn turtle" and eventually sink. Moreover, water accumulation on the car deck is not entirely deterministic as it depends on many stochastic influences, hence it is rather difficult to estimate the amount of water on deck, leading to vessel capsize. In cruise ships, a similar meachnism may lead to vessl loss, in this case related to the serive corridor on the main deck, which provides the conduit for water to spread longitudinally in the vessel and upflood via the vertical service trunks and stairwells.

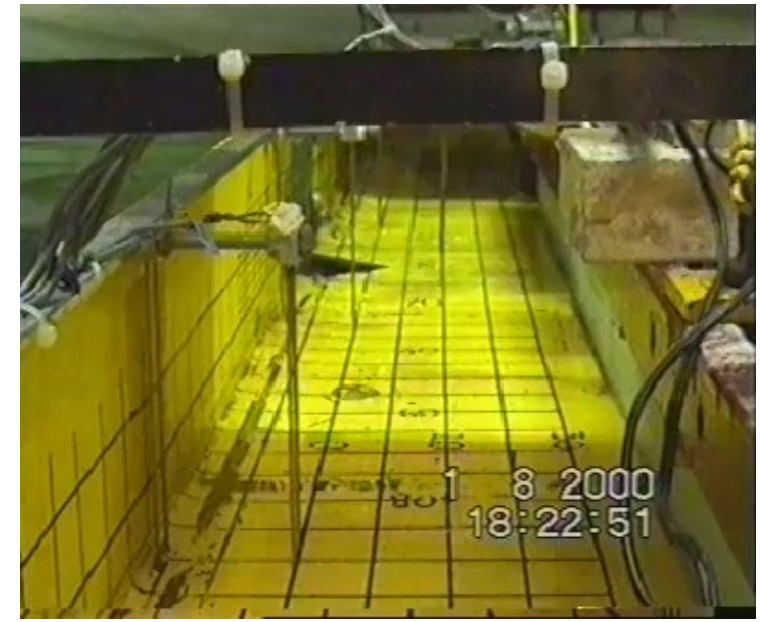

Figure 22: Typical Ro-Ro vessel set up for flooding capsize with water on deck

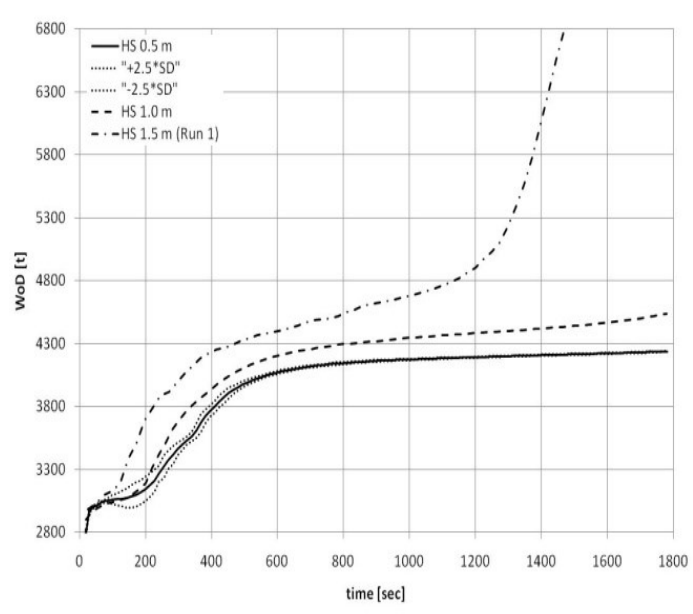

Figure 23: Typical time record of water on deck of a RoPax vessel, during progressive flooding, leading to capsize. 


\section{PROTEUS Software Suite}

\section{1: General Capabilities and Hisstory of Development Overview}

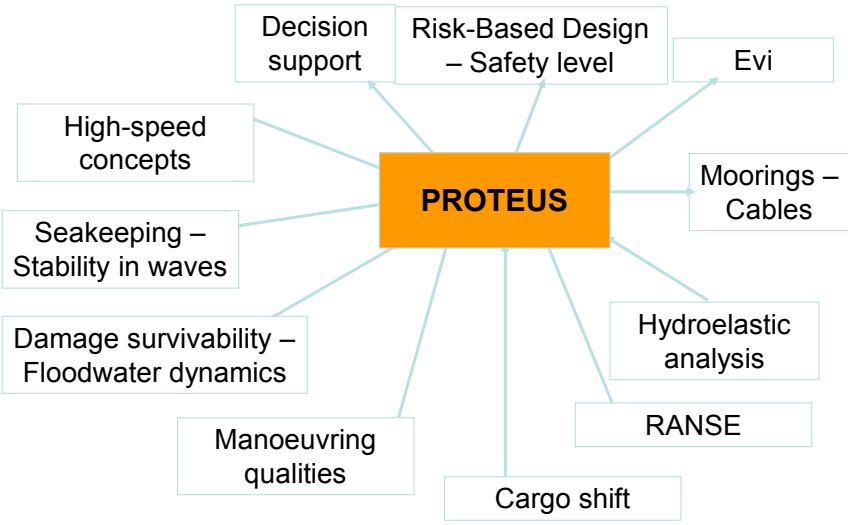

Figure 24: PRITEUS Software capabilities and history of development

Additional significant Strathclyde PhDcontributions over the different elements outlined in Figure 24 include: [Konovessis, D (2001)], [Tuzku, C (2002)], [Chai, S (2004)], [Strasser, C (2009)], [Gao, Q (2012)], [Cichowicz, J (2012)], [Tsakalakis, N (2012)], [Atzampos, G (2019) and [Karolius, K (2019)].

\section{2: Software Overview}

PROTEUS3 is capable of modelling in time-domain the dynamic behaviour of intact and damaged vessels in waves and has been validated against numerous model experiments and benchmark tests on various vessel types.

$\underline{\text { Summary of main features - Intact Stability and Seakeeping in seaways }}$

- Time-domain simulation, 6DOF, non-inertial systems of reference in regular and irregular waves, coupled with empirical and semi-empirical models for calibrated accuracy of predictions.

- Geometric non-linearities in hydrodynamics (restoring/Froude Krylov - instantaneous free surface)

- 2nd order drift forces, wind and current effects, water on deck

- Water Ingress/Egress and floodwater dynamics

- Resistance and propulsion characteristics; bilge keels, anti-roll fins, skegs; rudder and autopilot

- Multi-free surface engine able to accommodate detailed models of internal watertight architecture.

- Realistic modelling of openings capturing multidirectional collapse heads and variable leak rate flows.

- Individual control for opening activation/closing times.

- Ability to apply multiple external moments during the simulation to consider aspects such as wind loading.

- Detailed motion characteristics for specific user-defined points on a geometric model.

- Integrated Monte-Carlo sampling algorithm for random generation of collision and grounding damages.

\section{Summary of main applications}

- Seakeeping and Intact Stability: Capsize boundaries and criteria in different capsize modes; regulatory issues: weather criterion, parametric roll, behaviour in F/Q seas, $2^{\text {nd }}$ Generation Intact Stability Criteria; design support/evaluation, operability diagrams, weather routing, passenger comfort, slamming occurrence.

- Damage Stability and Survivability/Risk-Based Design: The PROTEUS software has been used extensively in the prediction of vessel motions and survival boundaries for estimating the outcome of Stockholm Agreement model tests, in particular PROTEUS I.

- Risk-Based Design: With flooding risk being the main contributor, PROTEUS offered key support in the the evolution and development of risk-based design and its implementation to industry in many newbuilding projects. 
- An important domain of application is the calculation of ship dynamic responses in relation to comfort analysis in a seaway.

- Application to several high-profile accident investigations to aid in understanding the evolution of flooding and eventual loss in a forensic manner.

- Applicable to vessel types ranging from small fishing vessels and high speed craft cargo and naval vessels cruise ships and RoPax.

- Emergency response, decision support and crisis management

Vessel Geometry and other Features

- Hull and compartments comprising the internal arrangement are accurately and efficiently defined by sections, reducing the calculation overhead imposed by geometric calculations. While shell thickness is handled directly in the definition of the hull, individual compartments each have an associated permeability.

- Compartment connections and openings: (a) via "Compartment Connections" such that they are handled as a single geometric object. Multiple compartments can be connected in this manner; (b) via specific openings (e.g. representing a hinged door, or a bulkhead opening) defined by the following parameters: Location, dimensions and orientation; connected compartments; collapse pressures and leakage rates (separate collapse pressures and leakage rates can be defined for each side of the opening (e.g. to handle the opening direction of a hinged door when it experiences flooding on only one side).

- Characteristics of the flooding process: forensic detail can be provided concerning floodwater paths, floodwater propagation, accumulation, flooding rates and frequency through openings.

- Loading condition: The vessel can be loaded via both point masses and fluid loads; a fluid load of a specified density is associated with an individual compartment.

\section{Contemporary Developments}

\subsection{Flooding Acccident Response}

In line with the EU 2011 Transport White Paper and the Horizon 2020 Transport Programme aim to "reduce accident rates, fatalities and casualties", Project FLARE contributes to ongoing efforts to increase the safety of shipping by targeting the risk of flooding with focus on emergency response, which is of paramount importance for passenger ships. Taking into consideration specific procedures adopted by IMO for risk assessment and existing instruments (such as the Formal Safety Assessment), the main overriding objective of FLARE is to develop a novel Risk-Based methodology, beyond the existing state-of-the-art, of 'live' flooding risk assessment, monitoring and management consistent with IMO high-level goals. Specific targets include:

- A risk aware life-cycle approach for effective flooding risk management, equally applicable to new and existing ships.

- The consideration of susceptibility to flooding due to collision, contact and grounding in order to better understand cause and effect of accidents.

- The study of the relationship between active and passive measures of risk mitigation and control on the one hand, and risk prevention measures on the other, in order to render risk-control measures post-accident most effective.

- The consideration of both "static" and "dynamic" risk reduction, mitigation or control measures.

- The development of methods to quantify the effect of all pertinent measures examined.

- The technical basis and a proposal for the revision of relevant IMO regulations towards a framework for lifecycle flooding risk management.

It is noted with interest that whilst understanding susceptibility to flooding is being targeted as a key objective to enable cost-effective consideration of all measures of flooding risk reduction, migration and control, the main emphasis of this large-scale EU project is damage limitation post-accident rather than on preventing the incident in the first place. The reason for this, as explained earlier, and all concerted efforts towards damage limitation post-flooding accidents, relate to the fact that the residual flooding risk in passenger ships is currently so high that any efforts to reduce this will be much more cost-effective than similar measures towards flooding risk prevention. This appears to be deviating from the axiom that prevention is better than cure but given the level of the residual flooding risk with large passenger ships presently, damage limitation is the right approach; hence the emphasis of FLARE on emergency response post-flooding accidents. The framework to achieve this derives from life-cycle considerations, as explained next. 


\section{Phase 1: Design Phase (Figure 25)}

Decisions made during the design phase, shape safety over the whole life cycle. In this respect, use of advanced tools and exploiting knowledge in all forms at the design stage is most effective and, hence, highly desirable. The derived knowledge could be used in further design iterations or indeed stored in a knowledge base for use over the life cycle of the vessel, including emergencies. Key to life-cycle risk management is the understanding that both the operational phase (monitoring and management of residual risk) as well as emergencies (emergency response) depend crucially on having identified during the design phase pertinent design vulnerabilities that lead to critical accident scenarios in pre-specified loading and environmental conditions and, on the basis of this, having taken appropriate measures to ensure:

(a) Vulnerabilities have been eradicated and design measures taken to reduce these.

(b) Evaluation of residual risk, including KPIs for monitoring purposes during the operational phase.

(c) Preparedness in addressing all identified critical scenarios in case of an emergency (emergency response).

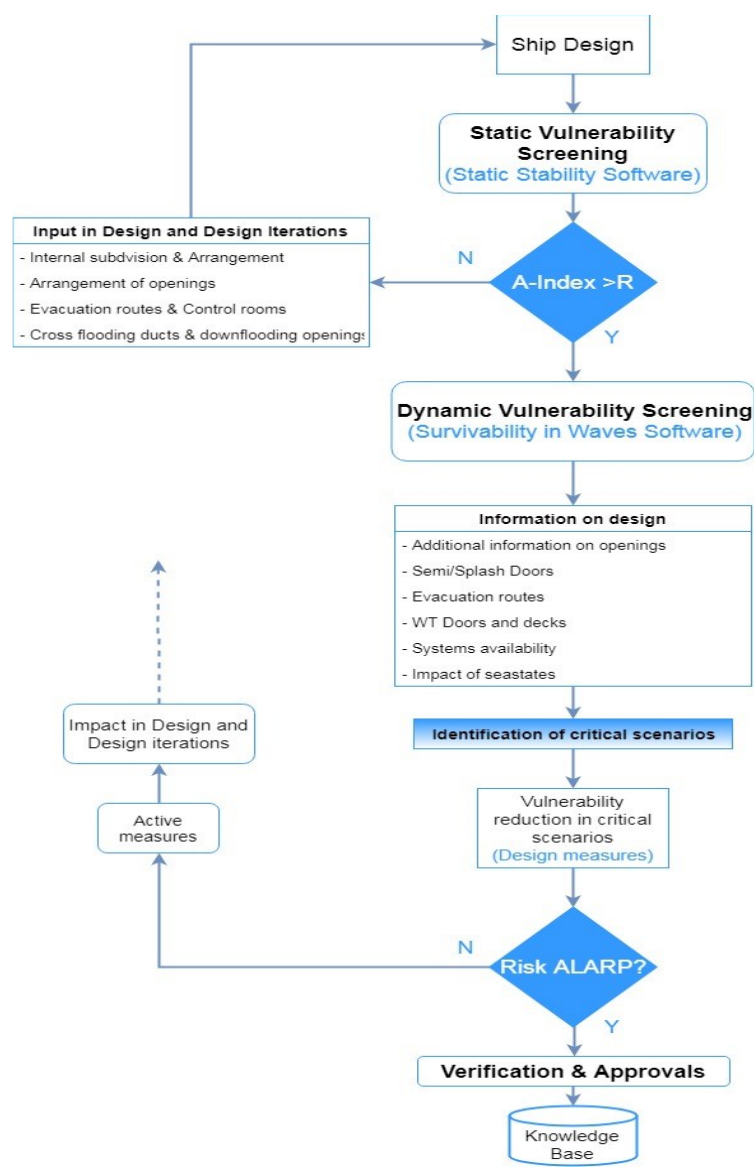

Figure 25: Design Phase 
Operation is the longest phase in the ship life-cycle, during which changes take place that have a direct impact on flooding risk. Therefore, risk must be monitored and reviewed to ensure changes in design / operation are reflected in the way risk is managed. This sounds straightforward in so far as changes take place in tangible, hence measurable, ship and environmental parameters, e.g., draft levels, loading condition, fluid tank levels, watertight door status, as well as prevailing wind and wave conditions.

On the other hand, there are many significant parameters and conditions, for example ship management practices, improving navigational equipment, training, safety culture and so on, which unarguably affect safety significantly. However, the impact of the majority of these factors on safety cannot, at present, be measured and hence monitored as there is not a system yet in place to assign risk credit/value to such influences. This will be one of the significant outcomes of the EU Project [SAFEMODE, EU H2020 (2019-3022)].

Notwithstanding this, monitoring what can be measured and is known to be KPI for flooding risk in real time is a step in the right direction to facilitate effective flooding risk monitoring, management and control.

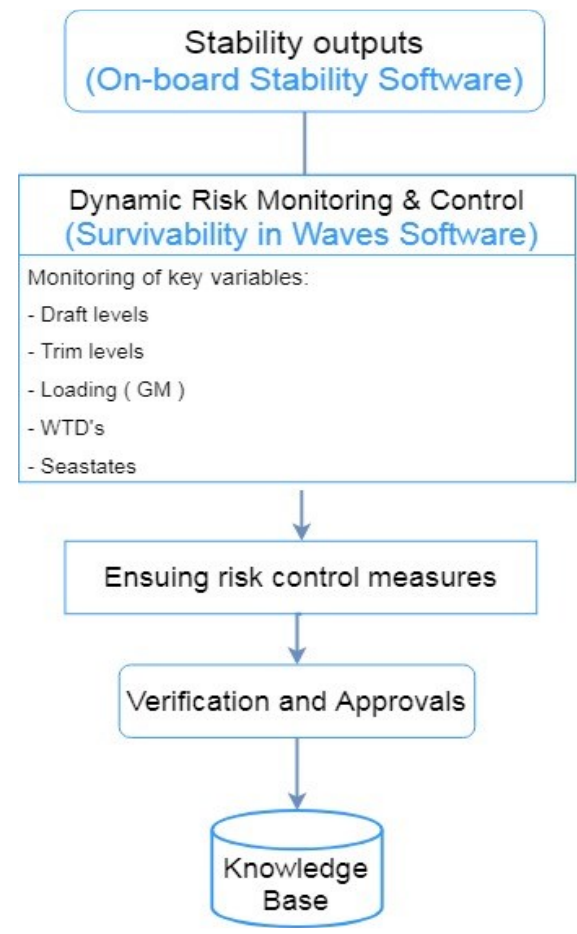

Figure 26: Operational Phase

\section{Phase 3: Emergency Response Phase (Figure 27)}

The emphasis, in this phase, is on ensuring that in any of the critical scenarios where ship stability and survivability is compromised, the ship will remain upright and afloat, with all safety systems available, for sufficient time to ensure safe evacuation of all the people on-board. However, similar to the operational phase most of the key elements affecting emergency response are not measurable/auditable, thus not providing any guidance to the operator in his strive to adopt cost-effective means to mitigate and control flooding risk in this vital last phase. Notably, new technologies are being explored to enhance situational awareness and guidance of evacuees during emergencies, e.g., EC-funded Project [saFEPASS, EU H2020 MG2.2 (2019-2022)]. In addition, new interventional measures are being introduced to the market, aiming to restore stability post damage or indeed control and mitigate flooding risk [Vassalos, D, Paterson, D and Boulougouris, E (2019)] and depicted in Figure 27. All these, provide a platform for transformational changes in the way damage survivability and emergencies onboard are currently being considered and will be systematically addressed in the not too distant future.

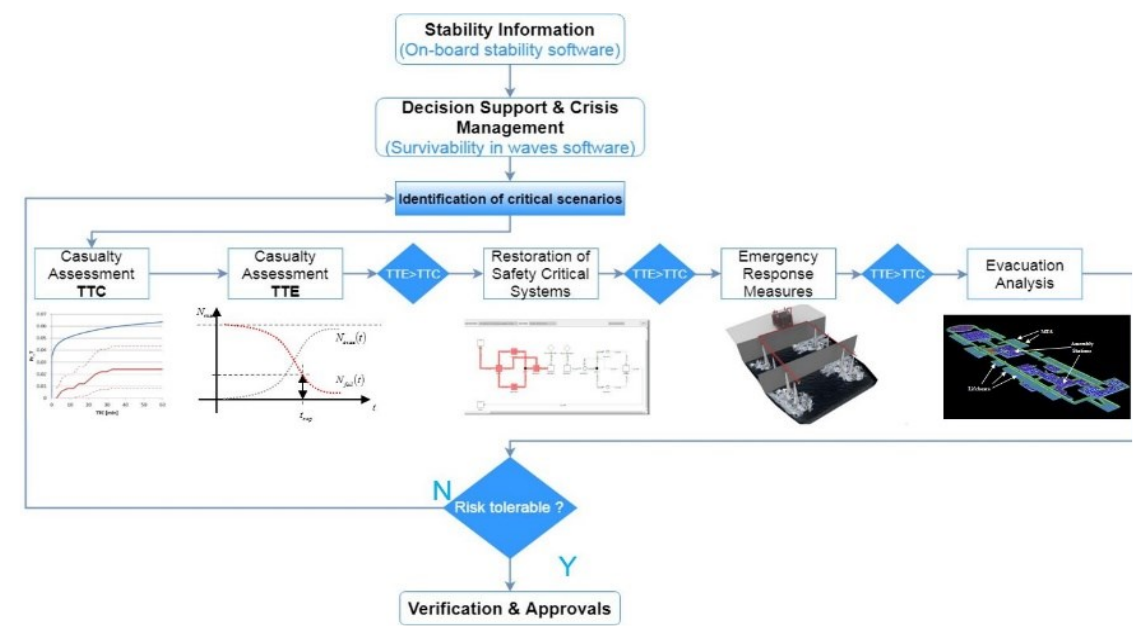

Figure 27: Emergency Phase 


\section{Direct Flooding Risk Estimation and Design Implementation}

It is worth emphasising that none of the questions and gaps arising from the aforementioned considerations of daamge stability and survivability in waves and Life-Cycle Risk Management considerations and framework (e.g., real time risk estimation and monitoring; risk merit attributed to pertinent human factors, etc.) are being addressed in terms of compliance with regulations. The level of knowledge, however, from the point of view of damaged ship dynamics and survivability in waves is at par with other performance assessments in Naval Architecture, pertaining for example to resistance and powering, seakeeping and manoeuvring. In this respect, achievement of the aforementioned goals in the holistic, goal-based and proactive approaches currently being adopted at IMO and seeping through in the industry, especially thrtoguh the newbuilding projects in the passenger ship industry, would ensure safety of human life commensurate with the safety expectations of today, by explicitly addressing all the key elements of risk, for total risk (Safety Level) estimation and for direct use in Risk-Based Design, as explained in [Vassalos, D, Jasionowski, A and Guarin, L (2008)].

With the focus in this paper on flooding risk, the best demonstration on consolidation of all contemporary developments and knowledge (regulatory, scientific, experiential) thought possible, is to consider a design implementation on a very large passenger ship, using first-principles tools for all the requisite analyses. As it could be readily understood, it is difficult to publish results on cruise ship survivability and for this reaason this example is "gold dust" for research. The same ship has been used extensively for beinchmark studies in ITTC. More details can be found in [Jasionowski, A (2007)], [Jasionowski, A (2009)] and [Chen, Tsakalakis, Jasionowski (2009)] results achieved during the SAFEDOR Project [SAFEDOR (2005-2009)]. The specific design highlighted here relates to the largest cruise ship ever built during the concept development phase, under the name Project Genesis, the general particulars of which are depicted in Figure 28 and Table 2 below.

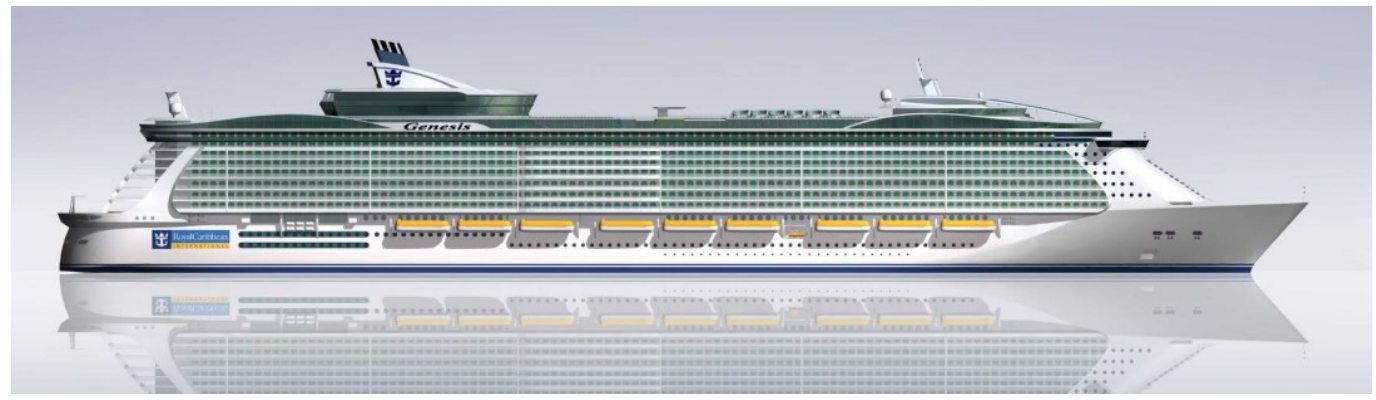

Figure 28: Project Genesis

\begin{tabular}{|l|r|}
\hline Length & $361 \mathrm{~m}$ \\
\hline Breadth & $47 \mathrm{~m}$ \\
\hline Draught & $9.15 \mathrm{~m}$ \\
\hline Gross Tonnage & 225,000 \\
\hline Air Draught & $72-65 \mathrm{~m}$ \\
\hline Number of Guests & 5,400 \\
\hline Number of Crew & 2,166 \\
\hline LSA Capacity & 8,460 \\
\hline
\end{tabular}

Table 2. Project Genesis, main particulars

As this vessel represents a step change in the size of mega-ships, including some uniquely innovative features, focusing on safety and adopting a performance-based (risk-based) design methodology came naturally. The task in hand is no less than ensuring that the largest ship ever built is also the safest (this theme was adopted by the RCCL design team as a way of reassuring the travelling public) and do so during the concept design stage, commensurate with all other design goals and functional requirements. The process adopted in this quest is briefly 
described in the following. The process is, of course, generic but the specific calculations and ensuing results pertain to Genesis.

\subsection{Total Risk (Safety Level)}

A common way of presenting graphically the chance of a loss (risk) in terms of fatalities is by using the socalled F-N diagram, the plot of cumulative frequency of $\mathrm{N}$ or more fatalities together with related criteria, [IMO (2009)], Figure 29. In addition, some form of aggregate information is used, such as the expected number of fatalities $\mathrm{E}(\mathrm{N})$, often referred to as Potential Loss of Life, PLL.

\section{Risk Model}

As a general statement, this entails a graphical, logical, statistical, mathematical, process-based construct enabling risk estimation. This may relate to one or all of the following:

- Frequency estimation alone of an event (e.g., fault tree for collision).

- The loss alone (event tree leading to estimation of PLL or actual loss).

- Both the above (e.g., "bow tie" or risk contribution tree).

- Conditional probability of survival (e.g. A-Index for collision, grounding or combination thereof, e.g., [eSAFE (2016-2018)]).

- Mathematical or numerical models, enabling direct risk estimation.

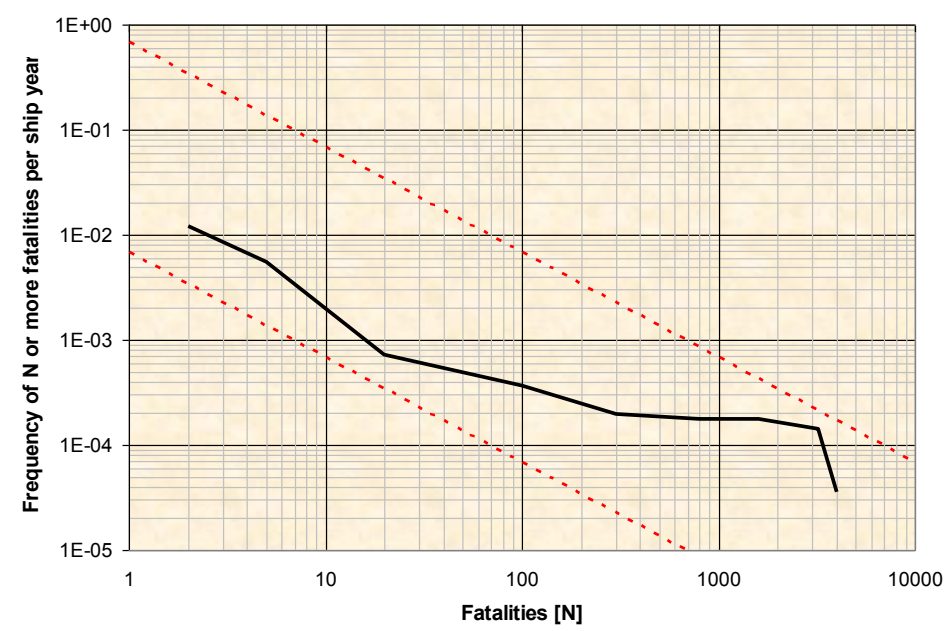

Figure 29: FSA cruise ships - Societal risk

In generic form, risk may be expressed as follows:

$$
\operatorname{Risk}_{P L L} \equiv E(N) \equiv \sum_{i=1}^{N_{\max }} F_{N}(i)
$$

Where $N_{\max }$ is the maximum number of persons on-board and the FN curve is given as:

$$
F_{N}(N)=\sum_{i=N}^{N_{\max }} f r_{N}(i)
$$

The frequency $f r_{N}(N)$ of occurrence of exactly $N$ fatalities per ship per year is modelled as follows:

$$
f r_{N}(N)=\sum_{j=1}^{n_{h z}} f r_{h z}\left(h z_{j}\right) \cdot p r_{N}\left(N \mid h z_{j}\right)
$$

Where, $n_{h z}$ is the number of loss scenarios considered and $h z_{j}$ represents a loss scenario pertinent to any of the principal hazards; furthermore, $f r_{h z}\left(h z_{j}\right)$ is the frequency of occurrence of scenario $h z_{j}$ per ship year and $p r_{N}\left(N \mid h z_{j}\right)$ is the probability of occurrence of exactly $\mathrm{N}$ fatalities, given that loss scenario $h z_{j}$ has occurred. As shown in Table 3, frequency estimates for flooding and fire hazards have been derived based on statistics. Efforts in the past to determine frequency of flooding events from first principles have not matured to an industry accepted standard (e.g., [HARDER (2003)] ) but there is a renewed impetus to address this in [FLARE, EU H2020 - MG2.2 
(2019-2022)]. In the interim, accident statistics provide the main source both for IMO instruments (SOLAS) and for research in this field.

\begin{tabular}{|c|c|c|}
\hline$j$ & Principal hazards, $h z_{j}$ & $\begin{array}{l}\text { Average historical frequency of occurrence, } \\
f r_{h z}\left(h z_{j}\right)\end{array}$ \\
\hline 1 & Flooding due to collision & 1.48E-3, (cruise ships), [SAFEDOR (2005-2009)] \\
\hline 2 & Fire & 0.92E-2, (cruise ships), [SAFEDOR (2005-2009)] \\
\hline 3 & Intact Stability Loss & ......... \\
\hline 4 & Systems Failure & \\
\hline
\end{tabular}

Table 3: Principal hazards

With passenger ships, flooding and fire casualties comprise over $90 \%$ of the risk and almost $100 \%$ of those leading to decisions to abandon ship, [SAFEDOR (2005-2009)]. Therefore, it would be possible to estimate the total risk of a passenger vessel by addressing these two principal hazards in a consistent manner and framework, allowing for their contribution to risk to be formally combined as implied in (15). In this paper, only collision flooding risk is being considered.

\section{Flooding Risk Analysis}

\section{Geometric Model}

To undertake a complete flooding risk analysis, involving all feasible scenarios (deriving from statistics) or indeed specific extreme scenarios to "stress-test" a given design, a complex geometric model is needed (including normally up to two decks above the bulkhead deck), which in the case of Genesis comprised 717 compartments with 1,160 openings, shown here in Figure 30.

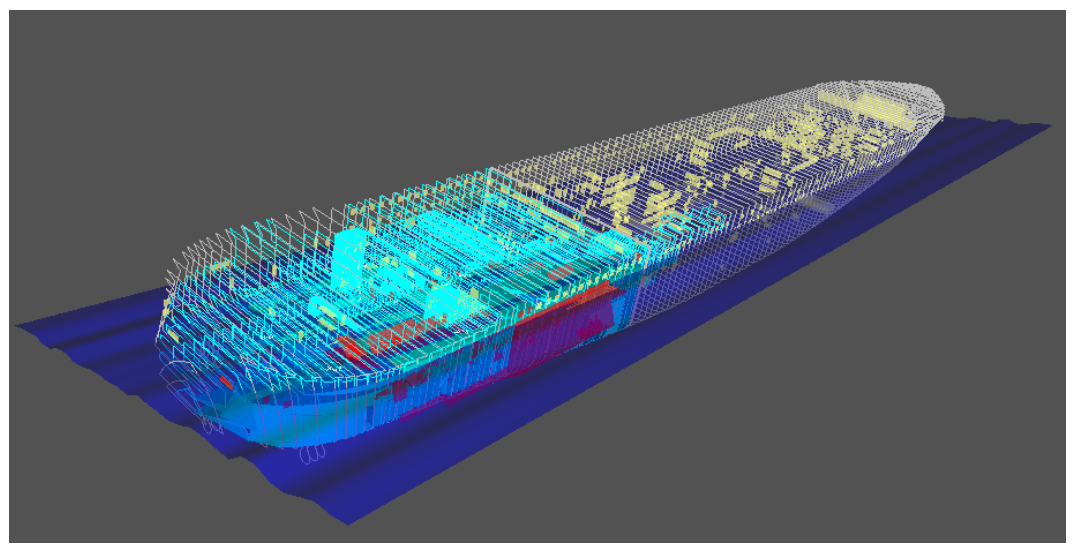

Figure 30: Flooding survivability analysis model for project Genesis, [SAFEDOR (2005-2009)]

Frequency Analysis $f r_{h z}\left(h z_{j}\right)$

As indicated earlier, only collision is being addressed here to allow comparisons between Project Genesis and the rest of the cruise ship fleet. Table 3 is used in this example, as records of 111 ship years of statistics, obtained from the owner, showed zero occurrences of flooding incidents. This relates to a frequency of 1.48E-3 per ship year (1 event every 571 ship years), deriving from statistics of the existing cruise ships at the time.

Consequence Analysis $p r_{N}\left(N \mid h z_{j}\right)$

Risk estimation as described above and detailed in [Jasionowski, A (2007)] for more specific scenarios, requires two parameters to be estimated as demonstrated in Figure 31 and further explained in the following. 


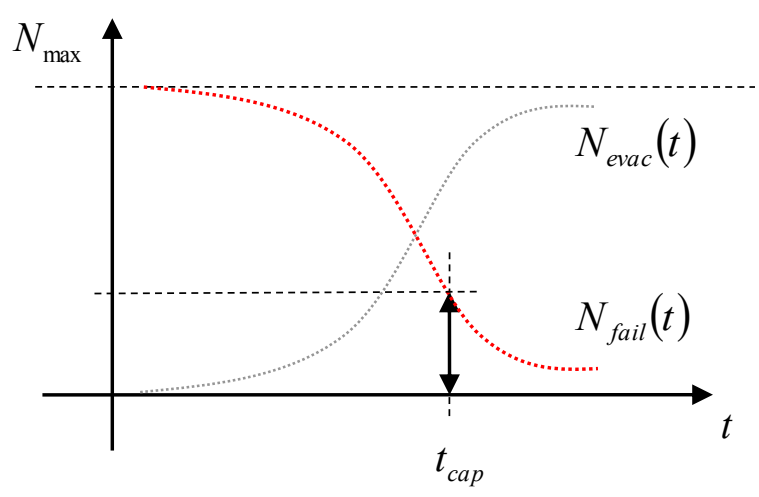

Figure 31: Evacuation Completion Curve and its Compliment

Time to Capsize (TTC):

The first parameter to be estimated relates to identifying those flooding scenarios where damage survivability is compromised (loss scenarios) and evaluate the time it takes for the vessel to capsize/sink in each one of these. The process involves generating a number of flooding scenarios by sampling the random variables, comprising: loading conditions, sea states and damage characteristics (location, length, height, penetration) according to damage statistics adopted in the IMO probabilistic regulations in SOLAS 2009, using Monte Carlo sampling. Each damage scenario is then simulated using explicit dynamic flooding simulation with PROTEUS3, aiming to identify potential loss scenarios, Figure 32 (generic) and Figure 33 (Genesis).

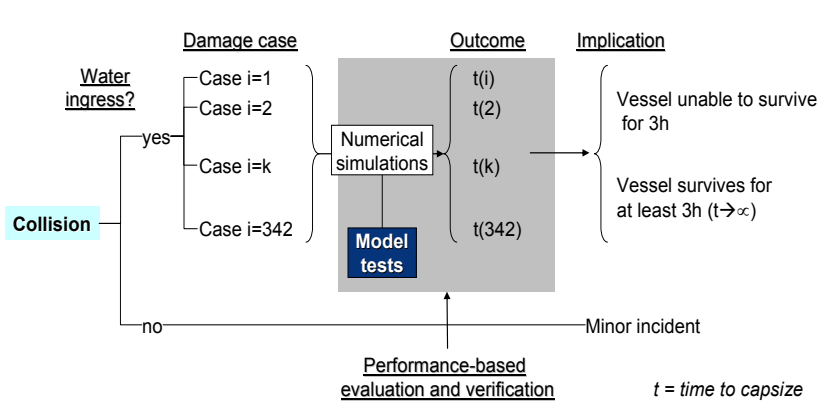

Figure 32: Monte Carlo simulation scheme - Collision

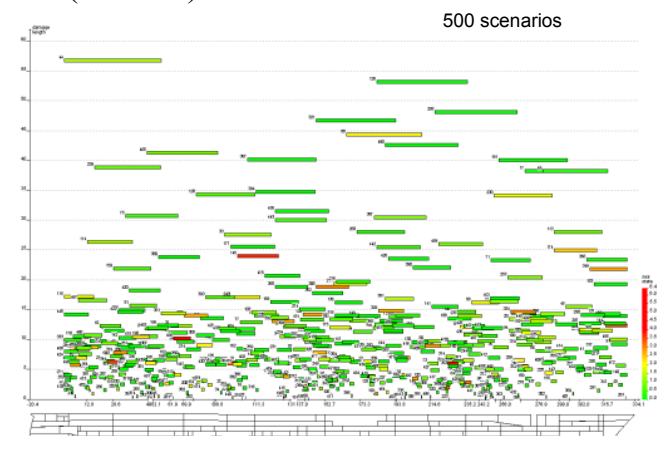

Figure 33: Monte Carlo simulation set up - collision, [SAFEDOR (2005-2009)]

Having identified these scenarios, the next step is a case by case explicit dynamic flooding simulation, accounting for potential transient- cross- and progressive-flooding, floodwater paths, impact of multi-free surfaces, influence of watertight and semi-watertight doors, location and criticality of openings (see e.g., Figure 34), all with the aim of providing feedback to the designer to address pertinent design vulnerabilities. At the end of this process, a number of scenarios will have been identified with a known time for capsize/sinking to take place to be further considered in assessing the expected time for all people on board to evacuate, accounting for the hazards presented by the propagation of floodwater in the internal ship environment, as explained in the following.
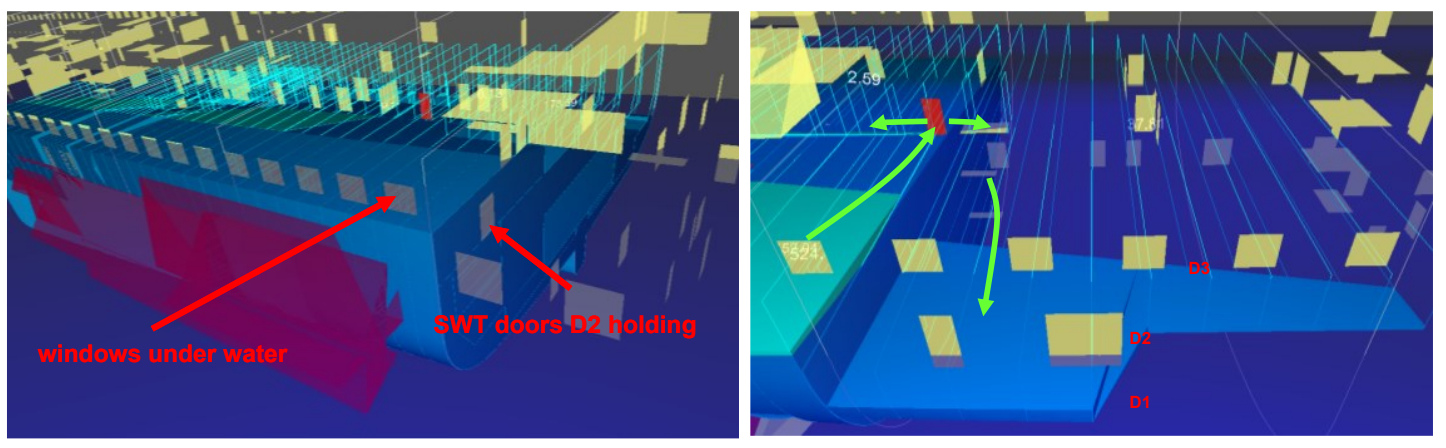
Figure 34: Time-domain simulation of the flooding process, (structural details and openings) [SAFEDOR

(2005-2009)]

A comprehensive experimental programme was also set up to verify the numerical simulations for representative progressive flooding and transient flooding scenarios, offering corroborative evidence, additional information and verification, hence confidence in the derived results (Figure 35).
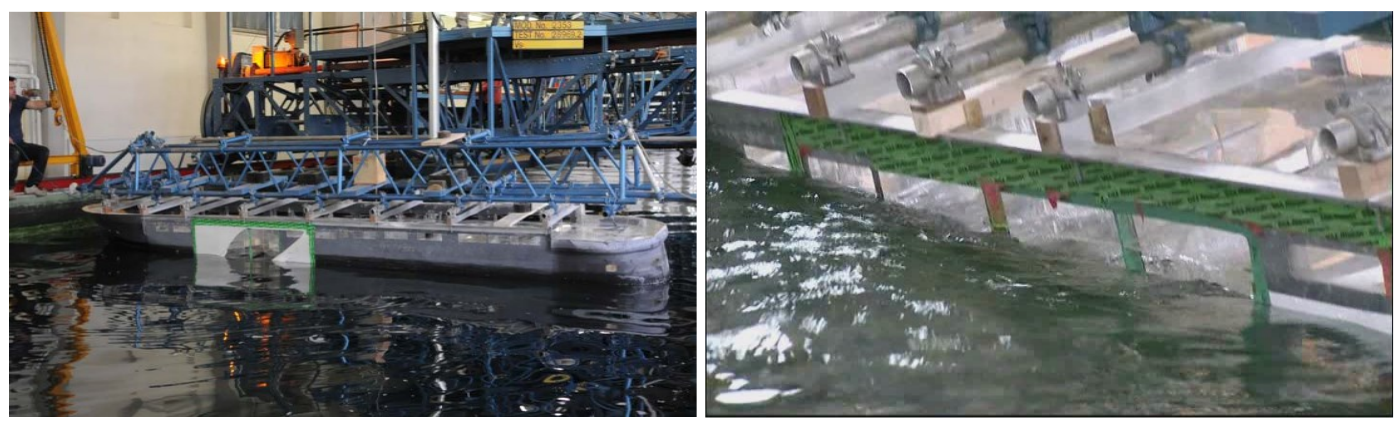

Figure 35: Damage survivability verification (Project Genesis)

\section{Time to Evacuate (TTE):}

This relates to the time required for orderly evacuation of passengers and crew in any given flooding emergency scenario, identified in the aforementioned process. To this end, use is made of advanced evacuation simulation software, in this case EVI, [Vassalos, Kim, Christiansen and Majumder (2001)]. EVI has been developed specifically for the marine industry with focus on large passenger ships. Hence, it accepts any accommodation layout in .DXF format and converts this to 3D VR environment. It is based on mesoscopic multiagent modelling, accounting for behavioural and environmental characteristics and their interaction and is capable of handling any passenger/crew/sea/hazard scenario. The term Evacuability has been coined to reflect ability to evacuate a ship environment within a given time and for given initial conditions, defined as follows:

$$
E=f\{\text { env,d,r(t),s[evacplan,crew,mii(g,y,hci)];t }\}
$$

Thus, Evacuability is a function of a set of initial conditions: ship environment (env), passenger distribution (d), passenger initial and in-situ response $r(t)$ and evacuation dynamics, $s\left(n_{i}\right)$, with suffix-i pertaining to evacuation plan, crew functionality and passenger mobility characteristics related to gender, age and mobility impairment, the latter depending on various handicaps, as depicted in Figure 36 next.

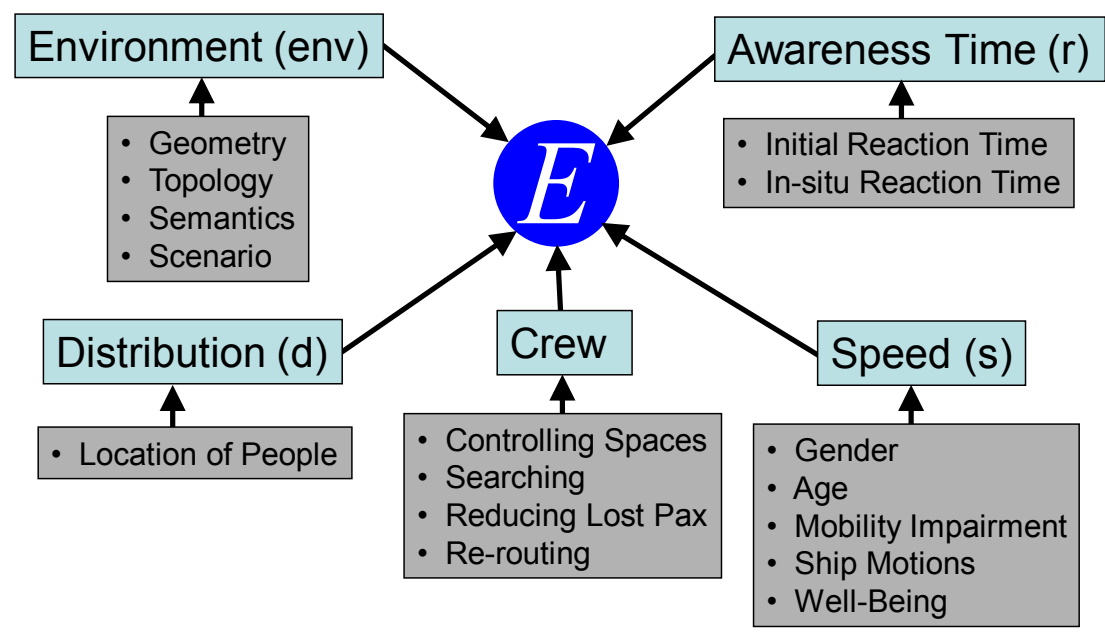

Figure 36: Parameter set for the advanced evacuation simulation software EVI

Evacuability provides a probability measure of passenger evacuation in a ship-sea environment, as explained in [Dogliani, M, Vassalos, D and Strang, T (2004)]. More importantly, EVI uniquely incorporates capability to 
estimate the effect of flooding hazards on the evacuation process. In the cases considered herewith, data from PROTEUS3 pertaining to the aforementioned loss scenarios are imported into EVI evacuation simulation environment, in the form of time series, as additional semantic information for the agents (evacuees). The agent model considers human behaviour in an evacuation scenario according to a small set of crucial characteristics, such as speed and awareness. A hazard within the evacuation environment will, therefore, affect these characteristics, changing the performance of the agents.

More specifically, EVI imports motion and floodwater data from PROTEUS3, pertaining to the flooding scenario being considered, which are processed to provide deck inclination to the horizontal (level) position. Using inclination, a correction factor is applied to the walking speed of the evacuee (agent) based on the results of research undertaken in the MEPDesign project [Vassalos et al. (2002)]. This has been described in detail in [Guarin et al. (2004)]. Thus, flooding data are used to affect the awareness and walking speed of agents, reducing it as they become affected by (being immersed in) floodwater, as illustrated in Figure 37, [L. Guarin, J.Majumder, V. Shigunov, G. Vassalos and D. Vassalos, (2004)].

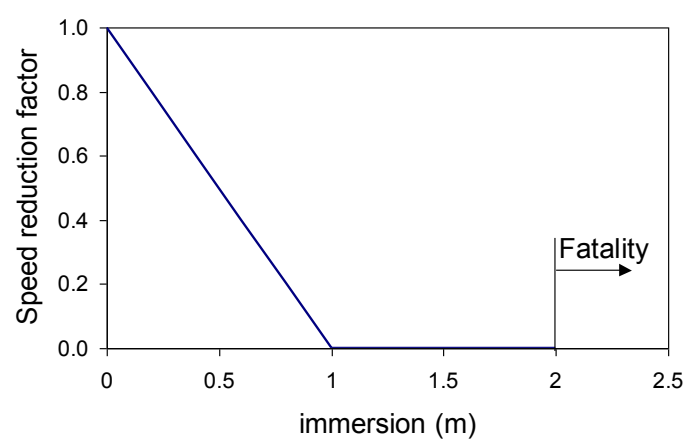

Deck inclination: asymmetric flooding will cause the ship to heel, making it more difficult for evacuees to walk, thus reducing the speed of agents.

Ship motions: ship motion will affect people orientation and movement; consequently, agents will advance more slowly, make wrong decisions, or fall over.

Inaccessibility: flooding renders some areas of the ship inaccessible. This entails that for people on lower decks, certain evacuation routes may become unavailable.

Figure 37: Flooding Hazards and their effect on the speed of evacuees

For all loss scenarios identified as described in the foregoing, evacuation simulation determines the time to evacuate (TTE). For the GENESIS Project, this involves both mustering (agents moving to assembly stations from the place of origin (Figure 38) as well as abandoning ship (Figure 39)), where loss of LSA as a result of damage has been accounted for through redundancies. If safety objectives were not met, the effectiveness of additional potential solutions, as indicated in the foregoing, were evaluated in the design stage until an acceptable solution were found.

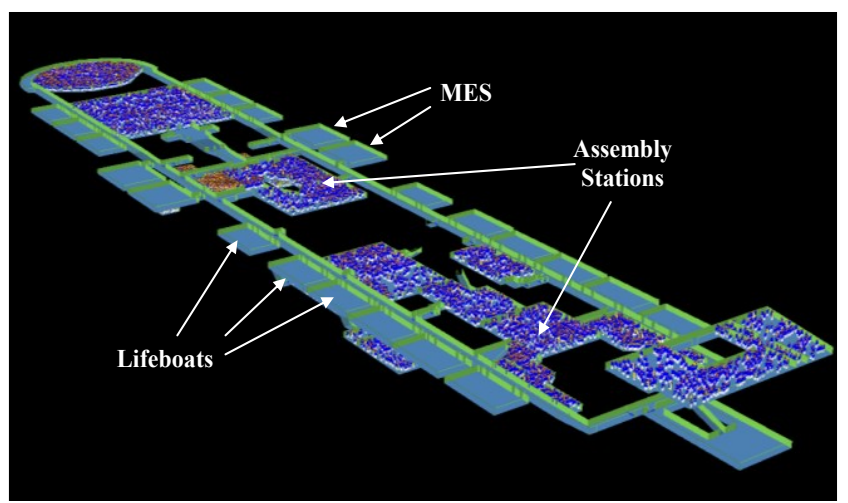

Figure 38: GENESIS mustering simulations with Evi 

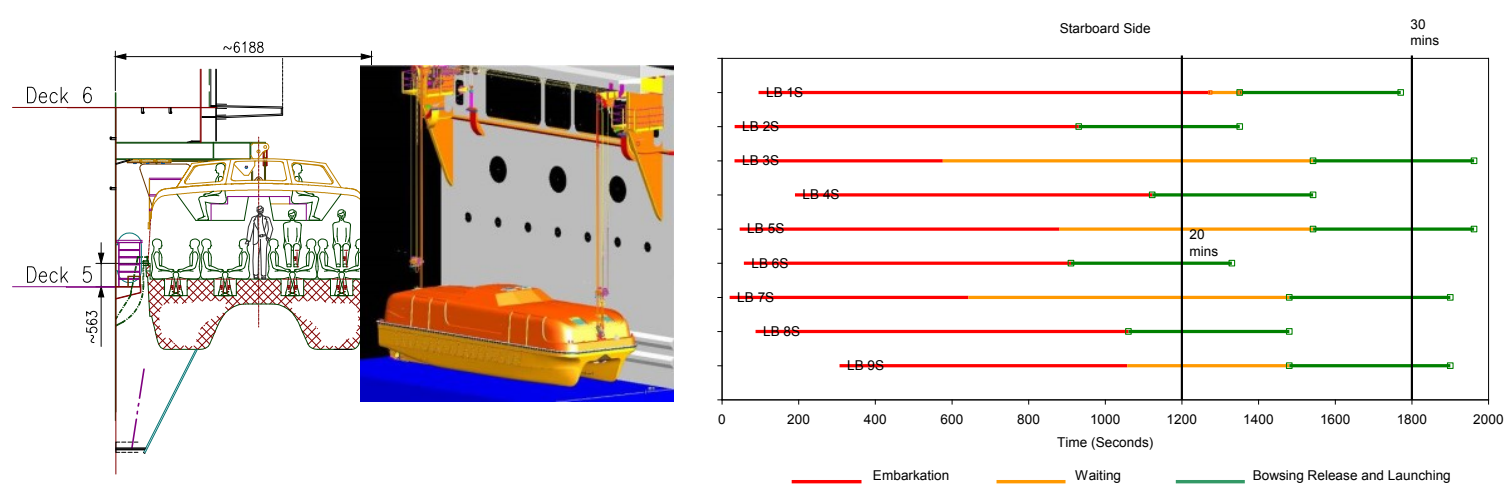

Figure 39: GENESIS abandonment studies

This iterative procedure, allowing for a direct link between a given scenario and risk, in terms of pertinent parameters affecting frequency and consequences as well as risk mitigation and control, affords an effective way of "de-risking" a passenger ship from flooding risk.

However, depending on the cost-effectiveness criteria being used, there will be a number of scenarios for which the tolerability criteria available, for example at IMO, are met and this enables calculation of Societal (Flooding) Risk, which in the case of the Genesis Project is provided in Figure 40 as an F-N curve together with results from the FSA on cruise ships [IMO MSC 85 (2009)]. These results clearly demonstrate that, in terms of flooding risk, Project Genesis has superior characteristics in comparison to the rest of the cruise ships in operation at the time. This diagram (together with a similar result for fire being used to aggregate the risk from the two principal hazards, thus leading to total risk estimation) hazards was used as the basis to present the Genesis Project Safety Level estimation in an afternoon meeting at IMO MSC 2007, a historic event in maritime safety evolution.

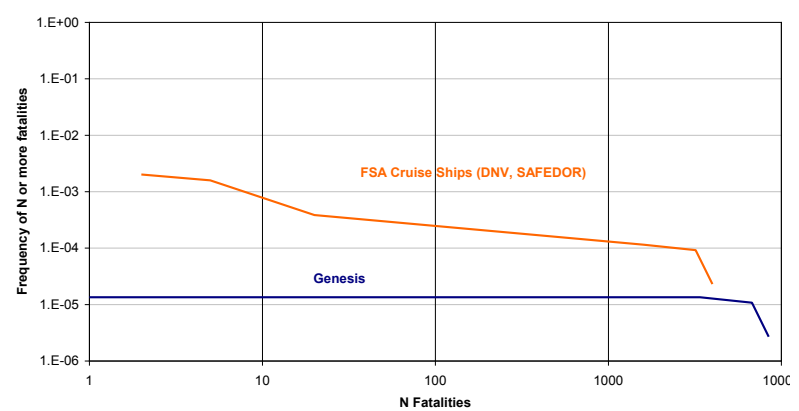

Figure 40: Societal Risk - Collision accidents, [SAFEDOR (2005-2009)]

\section{Live Flooding Risk Estimation and On-board Decision Support}

Having achieved the goal of designing a safe ship cost-effectively and go beyond all new and emerging safety requirements by utilising all available knowledge and technology, the question came naturally to the fore whether this extensive knowledge acquired during the design phase could be made the basis for estimating and monitoring flooding risk in operation to facilitate effective life-cycle flooding risk management, as described in the foregoing. In this respect, the approach adopted pertains to utilising the aforementioned estimation of the design flooding risk level as baseline and by monitoring those parameters, which are likely to affect deviations from such baseline, would lead to an effective means for live flooding risk monitoring and ultimately management. A simple example is provided in the following by way of demonstration, using the Index for damage survivability in waves as the flooding risk determinant, as explained in the following:

- Real time sensors and hardware integration (link to ship's SMS), measuring: tank levels, draughts, door states, water ingress alarms, wind and waves.

- $\quad$ Ship survivability in waves: Direct assessment of survivability in waves from the cumulative distribution for time to capsize [Vassalos, D (2016)]. 
- $\quad$ Criticality Assessment: Survival time (TTC) and evacuation time (TTE).

- Corrective action search: Evaluation of the impact of corrective actions, e.g. counter-ballasting, high expansion foam.

- Essential systems availability assessment post-flooding to enable such corrective actions.

On the basis of the foregoing a Decision Support System has been designed and installed on-board the first of the Genesis ships under the name of iStand [FLOODSTAND, (2009-2012)], as shown in Figure 41.
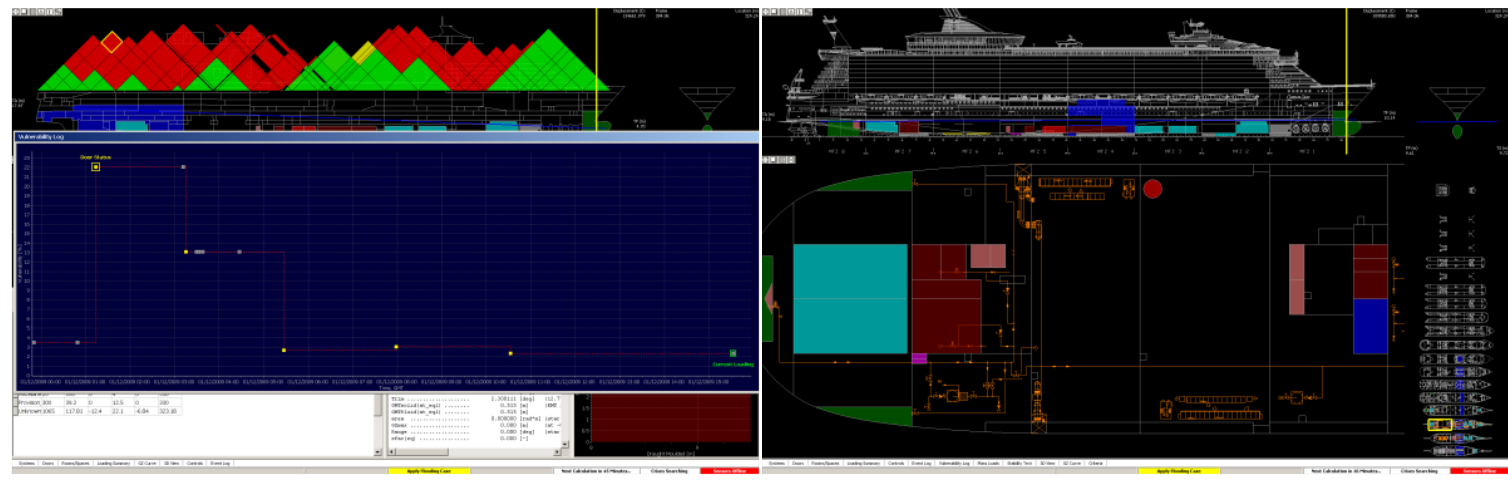

Figure 41: Live flooding risk monitoring and control on-board Genesis (iStand), [FLOODSTAND, (2009-2012)]

However, processing limitations at the time proved insurmountable and this pioneering innovation far ahead of its time, came to an end only to be awaken 15 years later through project FLARE [FLARE, EU H2020 - MG2.2 (2019-2022)], one of the key aims of which is live-cycle flooding risk monitoring and control.

\section{Concluding Remarks}

Based on the work presented in the foregoing, the following concluding remarks can be drawn:

- A painstaking evolutionary development in the subject of damage ship stability and survivability in waves is giving way to unprecedented scientific and technological changes at an ever increasing pace which, despite all the simplifying assumptions still embedded in the available "tool-set", facilitate step changes in addressing the key contributor to loss of life at sea, namely flooding risk.

- One key revelation of this new capability is the design vulnerability of passenger ships to flooding, following hull breach, a major issue that demands concerted effort and focus to bring the ensuing risk at par with the risk contribution of other principal hazards, such as fire.

- What is encouraging and stimulating is the fact that flooding risk is progressively being contained in a very cost-effective manner on newbuilding passenger ships. More latterly, similar cost-effective flooding risk control options are finding their way to implementation on existing ships, thus offering real possibilities for effective flooding risk containment across the whole industry for new and existing ships.

- With a clear trend towards life-cycle risk-based frameworks for flooding risk management, it is important to base such developments on clear understanding of the underlying principles and the intent of the ensuing regulations and risk criteria.

- Despite problems faced by the industry to cross the bridge from Rules-Based to Goals-Based (Risk-Based) standards, particularly concerning damage survivability, this paper demonstrates that pre-requisite scientific and technological developments are in hand for Risk-Based Design to be fully implemented in the maritime industry.

- The need, however, to inculcate all major stakeholders and practitioners in these new developments must remain a priority and clear targets set to facilitate the transition from prescriptive to goal-setting regulations, design and operation, a key objective of the new EC-funded project FLARE.

Acknowledgments: The support received over the years by the University of Strathclyde, the UK Department of Transport, the UK Maritime and Coastguard Agency, the European Commission and the wider maritime industry in undertaking the research work presented here is gratefully acknowledged. The author would like to single out RCCL for offering him the unique opportunity and experience of working with them for over 25 years and for being a member of their Maritime Advisory Board for the past 15 years, thus gaining unique insight, knowledge and understanding on how megaships are being designed and operated. Sincere thanks are also being extended to DNV GL and to Meyerwerft for stimulating discussions over the years and for their financial support (together with RCCL) in setting up the Maritime Safety Research Centre at Strathclyde, the first 
true Industry-Academia collaborative research initiative. Finally, I should like to single out my thanks to the EC for funding Project FLARE, the last building block in our quest for raising damage stability standards. Nothing would have been possible without the amazing young people (too numerous to single out) I had the fortune to work with at the Ship Stability Research Centre, the NAOME Department at Strathclyde, Safety at Sea Brookes Bell Ltd and more latterly the Maritime Safety Research Centre and Maritime Safety Innovations Ltd.

\section{References}

[Atzampos, G (2019)]: “A Holistic Approach to Damage Survivability Assessment of Large Passenger Ships”, PhD Thesis, University of Strathclyde.

[Chen, Q, Tsakalakis, N and Jasionowski, A (2009)]: "SAFEDOR Mathematical model of risk - physical experiments", D5.6.3, SAFEDOR-D-5.6.3-2009-04-30-SSRC-Experiments-rev-1.

[Cichowicz, J, Jasionowski, A and Vassalos, D (2010)]: "Uncertainty Assessment in Experiments on a Floating Body in Forced Roll Motion in Calm Water", Proceedings of the 10th International Stability Workshop, Wageningen, Netherlands.

[Cichowicz, J (2012)]: "Hydrodynamics of Damaged Ships", PhD Thesis, University of Strathclyde.

[Clarkson (2020)]: Clarkson Research Service Limited. Available from: https://sin.clarksons.net

[DGMOVE (2017-2019)]: “Assessment of Specific EU Stability Requirements for Ro-Ro Passenger Ships.

[Dillingham, J (1980]: “Motion Studies of a Vessel with Water on Deck”. Marine Technology, 18(1):38-50.

[Dogliani, M, Vassalos, D and Strang, T (2004)]: "Evacuation notation: A New Concept to boost Passenger Evacuation Effectiveness in the Cruise industry", Proceedings, 3rd International Euro-Conference on Computer Applications and Information Technology in the Marine Industries (COMPIT), May, Parador Siguenza, Spain.

[EMSA (2013-2015)]: "A Study to Assess Acceptable and Practicable Risk Levels for Damage Stability of Passenger Ships.

[EMSA (2009-2012)]: "Study of the specific damage stability parameters of Ro-Ro passenger vessels according to SOLAS 2009 , including water on deck calculation".

[eSAFE (2016-2018)]: "Damage Stability of Cruise Ships (eSAFE)", Joint Industry Project, Cruise Ship Safety Forum.

[FLOODSTAND, (2009-2012)]: EC, FP7 Project: "Standards for Casualty Mitigation, Damage Stability and Subdivision".

[FLARE, EU H2020 - MG2.2 (2019-2022)]: "Flooding Accident Response".

[GOALDS (2009-2013)]: "Goal-Based Damage Stability of Passenger Ships", DG Research, EU,

[Gao, Z, Vassalos, D and Gao, Q (2010)]: "Numerical simulation of water flooding into a damaged vessel's compartment by the volume of fluid method", Ocean Engineering 37 1428-1442.

[Gao, Z (2012)]: “A Hybrid Approach to Flooding and Damaged Ship Dynamics". PhD thesis, University of Strathclyde, 2012.

[Guarin, L, Majumder, J, Shigunov, V, Vassalos, G, and Vassalos, D. (2004)], "Fire and Flooding Risk Assessment in Ship Design for Ease of Evacuation", Proceedings, 2nd International Conference on Design for Safety, October, Osaka, Japan.

[Hamlin, NA, Lou, YK, Maclean, WM, Seibold, F, Chandras, LM, (1986)]: "Liquid sloshing in slack ship tanks - theory, observations and experiments", SNAME Transactions, Vol. 94, pp. 159-195.

[Himeno, Y (1981)]: "Prediction of ship roll damping - state of the art", Report No 239, University of Michigan, College of Engineering.

[HARDER (2003)]: "Harmonisation of Rules and Design Rationale": EC Contact No. GDRB-CT-1998-00028, Final Technical Report.

[IMO MSC 85 (2009)]: "FSA Cruise Ships", submitted by Denmark.

[Jalonen, R, Ruponen, P, Weryk, M, Naar, H and Vaher, S (2017)]: “A Study on Leakage and Collapse of Non-Watertight Ship Doors under Floodwater Pressure”, Marine Structures · January 2017,DOI: 10.1016/j.marstruc.2016.10.010

[Jasionowski, A (2001)]: “An Integrated Approach to Damage Ship Survivability Assessment”, PhD dissertation, University of Strathclyde.

[Jasionowski, A and Vassalos, D (2001)]: "Benchmark Study on the Capsizing of a Damaged Ro-Ro Passenger Ship in Waves", Final Report to the ITTC Specialist Committee on the Prediction of Extreme Motions \& Capsizing.

[Jasionowski, A (2005)]: "Survival Criteria for Large Passenger Ships”, SAFENVSHIP Project, Final Report, Safety at Sea Ltd.

[Jasionowski, A (2007)]: “Survivability Assessment - GENESIS”, SaS-RCGN10.

[Jasionowski, A (2009)]: "Physical Model Experiments on survivability of Genesis", RCGN14-Experiments-Report-24.

[Karolius, K (2019)]: "Risk-based, sensor-fused detection of flooding casualties for emergency response", PhD Thesis, University of Strathclyde.

[Kat, J de (1996)]: "Dynamics of a ship with partially flooded compartment", 2nd Stability Workshop, Japan.

[Konovessis, D (2001)]: “A Risk-Based Design Framework for Damage Survivability of Passenger Ro-Ro Vessels”, PhD Thesis, University of Strathclyde.

[Konstantopoulos, G (1987)]: “A Realistic Approach to Semi-submersible Stability”, PhD Thesis, University if Strathclyde.

[Letizia, L (1996)]: "Damage Survivability of Passenger Ships in a Seaway", PhD thesis, University of Strathclyde.

[NEREUS (1999-2002)]: "First-Principles Design for Damage Resistance against Capsize": EC Project CONTRACT No. G3RD-CT 1999-00029.

[Papanikolaou, A, Zaraphonitis G, Spanos, D, Boulougouris, E, Eliopoulou, E (2000): 'Investigation into the capsizing of damaged Ro-Ro passenger ships in waves", STAB, Launceston, Tasmania, Australia.

[Papanikolaou, A, Hamann, R, Lee, BS, Lemoine, L, Mains, C, Olufsen O, Tvedt, E, Vassalos, D and Zaraphonitis, G]: "GOALDS: Goal-Based Damage Stability of Passenger Ships", Transactions SNAME, 2013, Captain Joseph H. Linnard Prize. 
ROROPROB (1999-2002)]: "Probabilistic Rules-Based Optimal Design for Ro-Ro Passenger Ships": EU FP5 RTD Project G3RD-CT-2000-00030.

[Ruponen, P,, Kurvinen, P,, Saisto, I and, Harras, J (2013)]: “Air Compression in a Flooded Tank of a Damaged Ship”, Ocean Engineering, 57(2013), 64-71.

[SAFEDOR (2005-2009)]: “Design, Operation and Regulation for Safety,” Integrated Project, FP6_2 Contract TIP4-CT-2005516278, www.safedor.org.

[SAFEMODE, EU H2020 (2019-3022)]: "Strengthening synergies between Aviation and maritime in the area of human Factors" https://cordis.europa.eu/project/id/814961

[saFEPASS, EU H2020 MG2.2 (2019-2022)]: "Next generation of life Saving appliances and systems for saFE and swift evacuation operations on high capacity PASSenger ships in extreme scenarios and conditions".

[Shuhong Chai, 2004]: "Experimental Investigation on Hydrodynamic Properties of Ships in Damaged Conditions", PhD

Thesis, University of Strathclyde.

[Strasser, C (2009)]: "Behaviour of Damaged Ships during Progressive Flooding", PhD Thesis, University of Strathclyde.

[Tsakalakis, N (2012)]: "Performance- Based Damage Survivability of Passenger Ships and Design Implications", PhD Thesis, University of Strathclyde.

[Turan, O (1992)]: "Damage Survivability of Ro-Ro Passenger Vessels in a Seaway", PhD Thesis, University Strathclyde.

[Tuzku, C (2002)]: Probabilistic Rules for Damage Stability of RoRo Passenger Vessels", PhD Thesis, University of Strathclyde

[Van der Bosch, J.J. and Vugts, J.H. (1966)]: “On Roll Damping by Free-Surface Tanks”, Transactions, RINA, Vol. 108.

[Vassalos, D. and Turan, O. (1992)]: "Development of Survival Criteria for Ro-Ro Passenger Ships - A Theoretical Approach". Final Report on the S0T Ro-Ro Damage Stability Programme, University of Strathclyde.

[Vassalos, D., Turan, O (1994)]: "A realistic approach to assessing the damage survivability of Passenger ships", Transactions SNAME.

[Vassalos, D., Letizia, L (1995)]: "Formulation of a non-linear mathematical model for a damaged ship subject to flooding", Sevastianov Symposium, Kaliningrad.

[Vassalos D, Kim H, Christiansen G and Majumder J, (2001)]: “A Mesoscopic Model for Passenger Evacuation in a Virtual Ship-Sea Environment and Performance Based Evaluation”, Pedestrian and Evacuation Dynamics, April 4-6, 2001 Duisburg, www.safety-at-sea.co.uk/evi/publications.htm.

[Vassalos, D, Jasionowski, A (2002)]: "Damaged Ship Hydrodynamics", Proceedings of the 6th International Ship Stability Workshop, Webb Institute, New York, October 2002.

[Vassalos, D., Kim, H. S., Christiansen, G. and Majumder, J, (2002)]: A mesoscopic model for passenger evacuation simulation in a virtual ship-sea environment and performance-based evaluation, in Pedestrian and Evacuation Dynamics, 1st International Conference on Pedestrian and Evacuation Dynamics, Springer-Verlag, Berlin, Heidelberg, New York, 369-391.

[Vassalos, D, Jasionowski, A and Guarin, L (2005)]: "Passenger Ship Safety - Science Paving the Way", Proceedings of the 8th International Ship Stability Workshop, Istanbul Technical University, Istanbul, Turkey, 6-7 October 2005.

[Vassalos, D, York, A, Jasionowski, A, Kanerva, M and Scott, A (2006)]: Harmonised Damage Stability Regulations", STAB 2006, Rio de Janeiro, Brazil.

[Vassalos, D, Jasionowski, A and Guarin, L (2008)]: “Risk-Based Design: A Bridge too far?”, OC 2008 Seakeeping and Stability, Osaka, Japan.

[Vassalos, D, Jasionowski, A, York, A and Tsakalakis, N (2008)]: "SOLAS '90, Stockholm Agreement, SOLAS 2009 - The False Theory of Oranges and Lemons", 10th International Stability Workshop, Daejeon, Korea.

[Vassalos, D and Jasionowski, A (2011)]: Chapter 6: SOLAS 2009 - Raising the Alarm in Neves, M (Editor): "Contemporary Ideas on Ship Stability and Capsizing in Waves", Springer.

[Vassalos, D (2012)]: “Design for Safety, Risk-Based Design, Life-Cycle Risk Management”, Keynote Address, International Marine Design Conference, Glasgow, June 2012.

[Vassalos, D. (2014)]: "Damage Stability and Survivability - Nailing Passenger Ship Safety Problems", Journal of Ships and Offshore Structures, Volume 9, Number 3, June 2014, pp 237-256.

[Vassalos, D (2016)]: "Damage Survivability of Cruise Ships - Evidence and Conjecture", Ocean Engineering, Vol. 121, 15.07.2016, p. 89-978.

[Vassalos, D, Paterson, D and Boulougouris, E (2019)], "Water, Water Everywhere: Can High Expansion Foam Significantly Reduce Vessel Flooding Risk?”, MT Journal, April 2019, pp42-49.

[Wendel K. (1968)]: "Subdivision of Ships", Diamond Jubilee International Meeting, New York, pp 12-1 to 12-21.

[Zaraphonitis, G, Papanikolaou, A and Spanos, D (1997)]: "On a 3D Mathematical Model of the Damage Stability of Ships in Waves", STAB, Bulgaria.

[Zhang X, Lin, Z, Mancini S, Li P, Li, Z and Liu, F (2019)]: A Numerical Investigation on the Flooding Process of Multiple Compartments based on the Volume of Fluid Method", J. Mar. Sci. Eng. 2019, 7, 211; doi:10.3390/jmse7070211. 